\title{
DIANTHRONE PHOTOCHROMISM 1950-1970 $\ddagger$
}

\author{
T. Bercovici, R. Korenstein, K. A. Muszkat and E. Fischer
}

Department of Chemistry, The Weizmann Institute of Science, Rehovot,
Israel

\begin{abstract}
Photochromic phenomena are very briefly surveyed, with special emphasis on reversible photocyclizations on which many photochromic phenomena are based.

The chromic behaviour of dianthrone. DA. and its derivatives is reviewed. It is suggested that the coloured modification B is common to all cases observed, and that it is identical with the thermochromic coloured form.

A detailed study of the reversible and irreversible photoreactions, thermal reactions, and emission properties of DA and its derivatives is reported, based on the use of both stationary and flash methods, in a wide range of temperatures and solvents. All compounds are fluorescent and phosphorescent, and their triplet-triplet absorption spectra and triplet decay were observed at sufficiently low temperatures. With increasing temperature the triplet decays mainly via its conversion into $\mathrm{B}$, in some cases via a precursor $\mathrm{D}$. Both triplet $\rightarrow \mathrm{D}$ and $\mathrm{D} \rightarrow \mathrm{B}$ are strictly viscosity-controlled reactions. At still higher temperatures those derivatives not substituted in the 1 and 1 ' positions undergo irreversible photoreactions in competition with the formation of B. B itself is not affected by irradiation, apart from the low yield thermally-reversible formation of a free radical. Electron spin resonance measurements confirm the absence of any correlation between photochromism and e.s.r. signals.
\end{abstract}

In the derivatives substituted in the 1 and $1^{\prime}$ positions, only $B$ is produced. However, at still higher temperatures, and only in compounds methylated in the 1 and $\mathbf{1}^{\prime}$ positions, a second coloured modification $C$ is formed in competition with $\mathrm{B}$. The ratio $[\mathrm{C}] /[\mathrm{B}]$ is strongly dependent on the nature of the solvent, the temperature, and the wavelength of the photoactive light. The latter effect is due to the reverse photoreaction $\mathrm{C} \stackrel{\text { hy }}{\rightarrow} \mathrm{A}$, which is characteristic for the $\mathrm{C}$ form. This property of $\mathrm{C}$ was used in order to determine its absolute absorption spectrum in various solvents. The quantum yields of photocoloration are around 0.6 and decline to practically zero at very high viscosities, while the quantum yield of photoerasure of $\mathrm{C}$ is about 0.05 but goes down with the temperature only to a limited extent.

Low-temperature n.m.r. and i.r. measurements of $\mathbf{B}$ and $\mathbf{C}$ were carried out.

The tempting proposal that $B$ has the cyclic structure analogous to $4 \mathrm{a}, 4 \mathrm{~b}$ dihydrophenanthrene cannot be upheld in view of the thermal and photochemical stability of B towards oxygen. It may hold for the $\mathrm{C}$ isomer, and could explain the n.m.r. results obtained for C. The cyclic structure should be an intermediate in the photo-oxidation of DA to helianthrone, but has as yet to be detected. The structure of $\mathbf{B}$ thus remains open for discussion.

The fluorescence of substituted dianthrones is blue-shifted on cooling, again in what seems to be a pure viscosity effect, probably connected with steric relaxa-

$\dagger$ In memoriam Yehuda Hirshberg, 1903-1960.

$\ddagger$ This is Part VI in the series 'Photochromism in Dianthrone and Related Compounds'. Part of the material described here has been published in two preliminary notes ${ }^{1,2}$. 


\section{T. BERCOVICI, R. KORENSTEIN, K. A. MUSZKAT and E. FISCHER}

tion phenomena in the system: excited solute-solvent. The quantum yields of fluorescence pass through a maximum, again by a mechanism connected with the above relaxation.

\section{INTRODUCTION}

Some twenty years ago my late colleague Hirshberg, to whom this lecture is dedicated, suggested the name photochromie (in French) to describe a phenomenon discovered by him, namely the strong coloration which is produced by u.v. irradiation of solutions of certain compounds, and which fades in the dark, at higher temperatures.

For some psychological reason the name photochromism was soon widely accepted in the world and is now used to describe any reversible light-induced changes of the visible absorption spectrum of compounds in solution. The scope of this field is best indicated by the forthcoming publication of a large volume dedicated solely to this subject. This follows a considerable number of review articles which have appeared in recent years $^{3-5}$. There is therefore no point in adding another review, and I decided to devote most of this article to the class of compounds first named "photochromic' by Hirshberg, namely the 'dianthrones'. But first let us glimpse at the chemical changes on which some cases of photochromism are based. The definition given above is purely descriptive and therefore includes a variety of mechanisms, almost as wide as the range of reasons for the 'colour' of compounds.

Obviously we can expect very pronounced changes in the absorption spectrum, i.e. 'coloration' or 'decoloration', only in reactions in which severe electronic changes take place in the system. This is why cis-trans isomerizations are not accompanied by strong spectral changes. Perhaps the most straightforward photoreactions involving electronic changes are reversible photo-ionizations ${ }^{6}, \mathbf{R X} \stackrel{\text { kै }}{\rightleftarrows} \mathbf{R}^{\oplus}+\mathrm{X}^{\ominus}$, and reversible photodissociations into stable radicals ${ }^{7}, R_{2} \underset{\Delta}{\stackrel{h v}{\rightleftarrows}} 2 R$ : Both reactions involve the appearance of absorption bands in the visible region. They are not reversible photo-

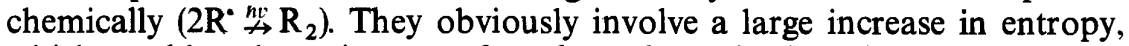
which enables the existence of a thermal equilibrium between the two species even when the enthalpy difference is large. Thus for $\mathbf{R}=$ triphenylimidazolyl radical ${ }^{7}$, with a peak at $550 \mathrm{~nm}, \Delta H$ is about $26 \mathrm{kcal} / \mathrm{mole}$, while $\Delta F$ is only $11 \mathrm{kcal} / \mathrm{mole}$, and 'thermochromism', i.e. thermal equilibrium between colourless and coloured forms, is also observed. Some e.s.r. studies greatly aided the study of this system, both regarding photochromic and thermochromic behaviour. The energy barrier of the thermal back reaction in this case is about $10 \mathrm{kcal} / \mathrm{mole}$, sufficient to slow down the reversion enough to allow detection of photochromism even at room temperature.

Among the intramolecular reactions accompanied by pronounced electronic changes, those involving the fission or formation of a ring system are most prominent. It seems that in most cases the appearance of absorption in the visible range is due to the formation of a polymethine system ${ }^{5}$, as shown in the following schematic reactions. The coloured isomer is underlined. 


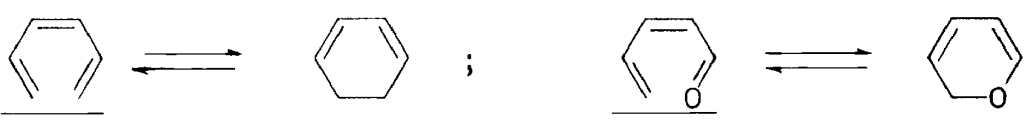

Some real examples are the photoformation of $4 \mathrm{a}, 4 \mathrm{~b}$-dihydro-phenanthrenes ${ }^{8}$ (peaked at $450 \mathrm{~nm}$ ), and dihydropyrenes ${ }^{9}(670 \mathrm{~nm})$,
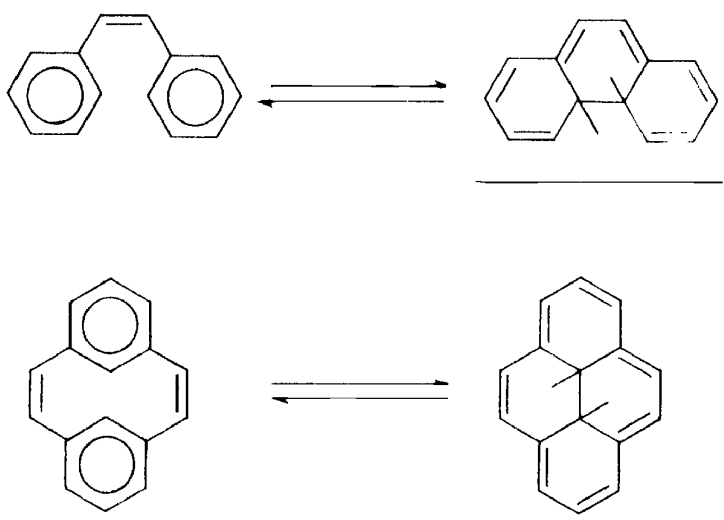

the chromene and pyran systems ${ }^{10}$

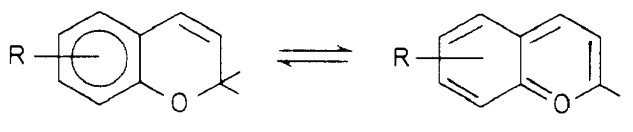

and, last but most important for practical applications, the spiropyrans, whose photochromic behaviour was first observed in our laboratory ${ }^{3}$.
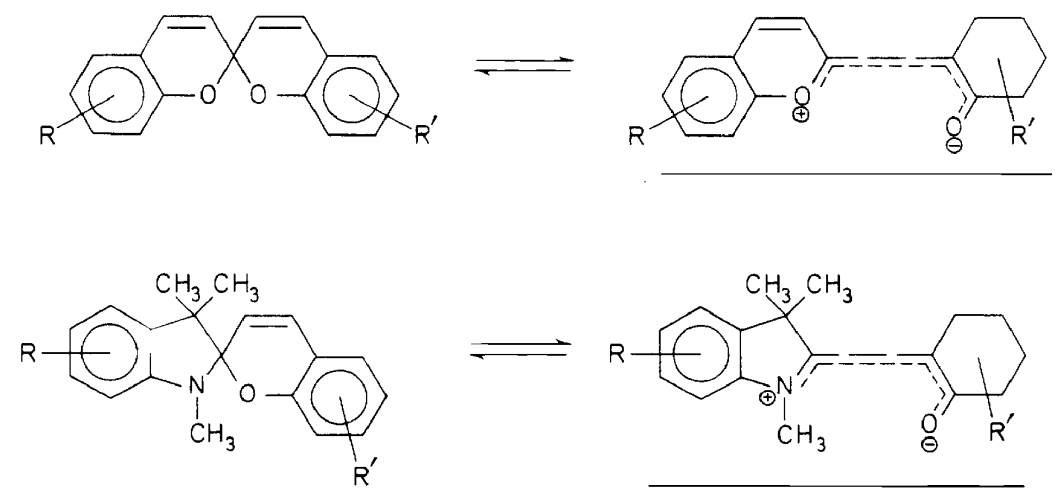

Several of these systems are photoreversible, i.e. A $\stackrel{h y}{\rightarrow}$ B, B $\stackrel{\text { hy }}{\rightarrow}$ A. In fact the most prominent applications of photochromism make use of this photoreversibility, in particular in connection with microphotography.

So much for the review part. The dianthrones, although the first photochromic materials to be reported, remained dormant for a number of years after 1953, except for two papers by Hirshberg, and several by Kortüm and 


\section{T. BERCOVICI, R. KORENSTEIN, K. A. MUSZKAT and E. FISCHER}

co-workers. However, in the midsixties interest in these systems suddenly grew, and it seems that several groups, including my own, started extensive investigations in this area. The results have either been published or will soon appear in print, and of course reflect the great advances in techniques and ideas during the last decades. I shall refer to the work of other laboratories in the course of the description of photochromism in these compounds.
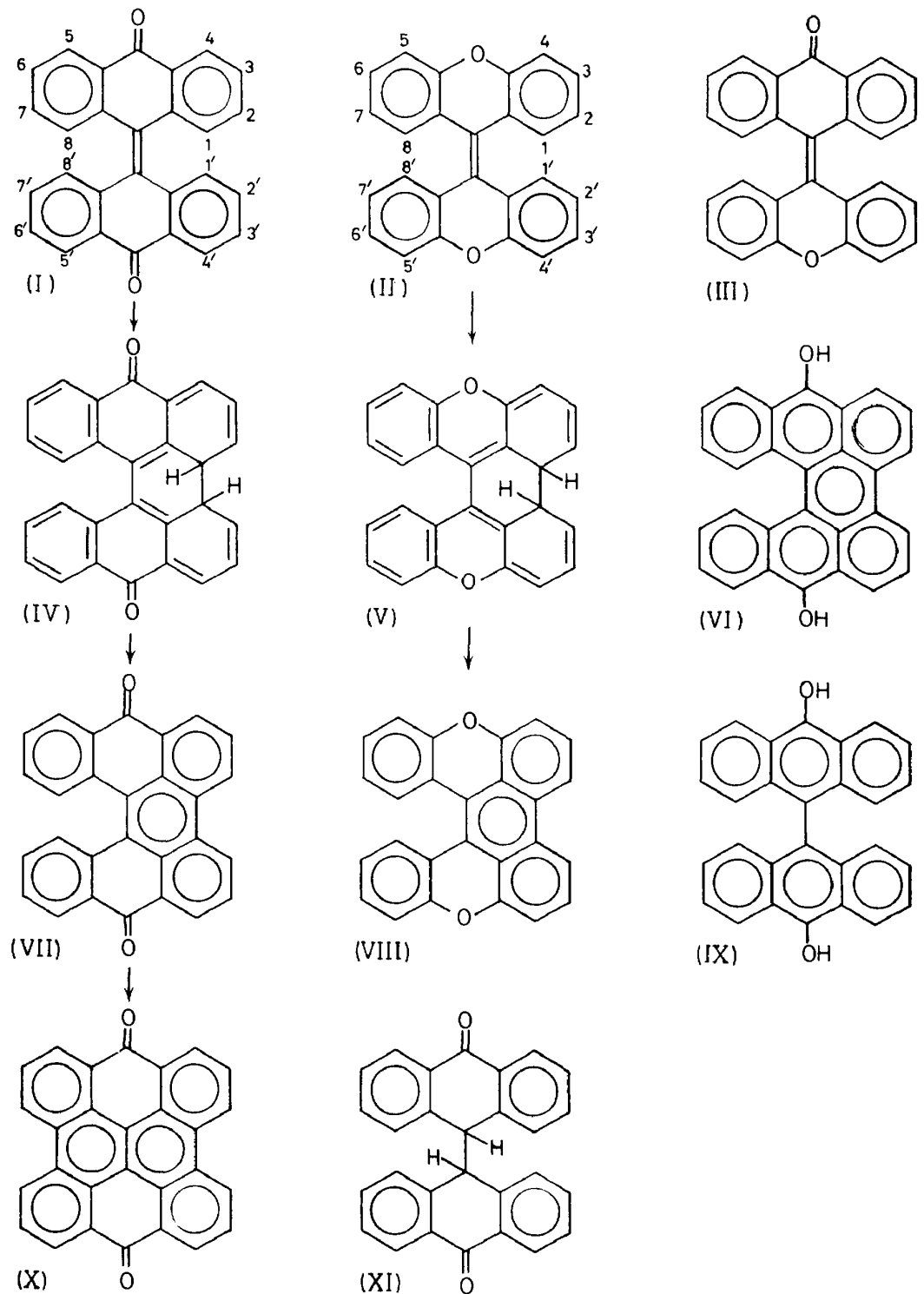

(III)<smiles>C1=CC2C3=C2C2C=Cc4cccc5c4C(=C2c2ccccc2OC3=C1)c1ccccc1O5</smiles>

(V)<smiles>[Te][Te]</smiles><smiles>Oc1c2ccccc2c2cccc3c4c(O)c5ccccc5c5c(cccc1c32)-c54</smiles><smiles>Oc1c2ccccc2c(-c2c3ccccc3c(O)c3ccccc23)c2ccccc12</smiles>

(VIII)<smiles>O=C1c2ccccc2C(C2c3ccccc3C(=O)c3ccccc32)c2ccccc21</smiles> 


\section{DIANTHRONE PHOTOCHROMISM 1950-1970}

The discovery of photochromism in compounds I. II. III. and their derivatives goes back to earlier work on the thermochromism of these compounds. This was shown by Kortüm to be due to a thermal equilibrium between two forms of the respective compound of which the coloured one is higher in energy by about $5 \mathrm{kcal}$ mole.

Another observation which preceded that of photochromism was the light-induced oxidation of dianthrone. I. to helianthrone. VII. and naph thodianthrone. $\mathrm{X}^{11}$. and the related reaction with dixanthylene. II. to give VIII. It was therefore natural to suggest that this photo-oxidation passes through the intermediates IV or V. followed by dehydrogenation. Indeed. if two of the four hydrogens adjacent to the central double bond are exchanged with other atoms or groups. the oxidation is greatly inhibited.

Such a sequence was indeed hinted by Brockman ${ }^{11}$ back in 1948. and eventually received considerable support by the photocyclization of stilbene to dihydrophenanthrene. with the subsequent oxidation to phenanthrene. mentioned before.

All this still does not concern the nature of the coloured forms. both thermochromic and photochromic. But then it was suggested by Schönberg ${ }^{12}$ and by $\mathrm{us}^{8}$ that these hypothetic intermediates IV and V are actually the coloured isomers. again in analogy with the coloured dihydrophenanthrenes. As far as absorption spectra are concerned this looked like a good suggestion and it was taken up more or less enthusiastically by other groups. including the one headed by Günthard in Zürich. who concluded ${ }^{13}$ that only the spectrum calculated for IV fits the experimental curves.

This structure would be in line with the ideas about reversible photocyclization given above. and I shall refer to it below. Two other methods of producing coloured modifications of the dianthrones have been described. One is based on the low-temperature hydrolysis of solutions of dianthrones in sulphuric acid ${ }^{14}$, and the other one on the low-temperature electrolytic oxidation of dianthranol ${ }^{15}$. IX. It is plausible that these two coloured forms are identical with the "thermoshromic" form. which in turn is identical with the photochromic one. In all cases we seem to be dealing with a high -energy form $B$ of the compound, which is formed either by way of a thermal equilibrium $\mathbf{A}=\mathbf{B}$ in thermochromism. or according to Ostwald's step rule. in the other cases.

So much for the unified picture of the various 'chromic' forms of these compounds. However. let me say at once that despite the efforts which I shall describe. the structure of B is still very much an open question.

\section{EXPERIMENTAL}

Materials-Compounds were synthesized according to the literature ${ }^{16}$. except dianthrone and its $1.1^{\prime}$-dimethyl derivative. which were commercial products recrystallized before use, Alliphatic and alicyclic hydrocarbon solvents were purified by passage through a column of Woelm alumina. Alcohols and triacetin (Fluka) were fractionally distilled. Methylene chloride was of spectroscopic quality (Fluka). 2-Methyl-tetrahydrofuran (Fluka) was 
first passed through a column of Woelm alumina and then distilled on the high-vacuum line from alumina into cells containing the solute. The cells were fused off. Hydrocarbons were distilled in the same way, from a $\mathrm{K}-\mathrm{Na}$ alloy.

Low temperature u.v., flash, and emission spectrophotometry, and irradiations - These were as described earlier ${ }^{17,18}$, but the more recent cooling technique ${ }^{19}$ was employed. A Cary 14 served for spectrophotometric measurements.

Infra-red measurements at low temperatures-Cavity cells (Barnes Eng. Co.,) of $0.1 \mathrm{~mm}$ light path were used in a copper block cooled with liquid air ${ }^{19}$. The copper block was insulated with styrofoam. The openings for the light beam were sealed with single plates of IRTRAN and sodium chloride, one on each side, which were flushed continously with dry nitrogen. Irradiations were carried out by moving the whole unit out of the cell compartment to a nearby mercury lamp. This arrangement was used successfully at down to $-105^{\circ} \mathrm{C}$. No lower temperatures were employed because of the limitations by the solvents used.

In the spectral range in which Infrasil can be used (below $3 \mu$ ), a quartz Dewar with Infrasil windows was used with a 1 or $10 \mathrm{~mm}$ Infrasil cell in a copper block, similar to the arrangement used in the ultra-violet. An Infracord 237B spectrometer was employed throughout.

The e.s.r. measurements-These were carried out in a Varian E-3 spectrometer. 3 or $4 \mathrm{~mm}$ tubes were irradiated inside the cavity and cooling accessory. At temperatures below $-160^{\circ} \mathrm{C}$ our own cooling system was used ${ }^{19}$. An Osram HBO-200 mercury arc in a Wild lamp house was used for irradiation.

The n.m.r. measurements - In view of the difficulty in irradiating the n.m.r. tubes in the cavity, measurements were made on solutions in tubes which had previously undergone irradiations, at the temperatures required by the system. After irradiation the tubes were kept in liquid air until they could be measured. Before introducing them into the precooled n.m.r. instrument they were immersed in a cooling bath kept at a temperature $10 \mathrm{deg}$. below that of the instrument, wiped dry with tissue paper and quickly inserted into the spectrometer. In this way thermal decay of the coloured isomers was reduced, though not completely eliminated.

Earlier measurements were done on the Varian A-60, and later ones on the Varian HA-100. The solvent used was deuterated chloroform, either alone or mixed with carbon disulphide, to allow work at the lower temperatures needed for the B isomer. (Deuterated methylene chloride was not available at the time, but will be used in the future.) The accuracy of the measurements was limited by the low solubility of the compounds, and by the technical difficulties involved in transferring the n.m.r. tubes at low temperatures.

\section{General}

\section{RESULTS AND DISCUSSION}

used:DA-dianthrone (compound I), TMD—1,3,1',3',-tetramethyldianthrone, DMD-1,1'-dimethyl-dianthrone. (In the absence of clear-cut information about the configuration in these and other derivatives, we assume arbitrarily the cis configuration with regard to the central double bond. In earlier 
papers we assumed the trans configuration, so that DMD would have have been denoted 1,8'-dimethyl-DA.) Solvents used were: $\mathrm{MCH}$-methylcyclohexane, MTHF-2-methyltetrahydrofuran, 2-MP-2-methylpentane, 1-P-1-propanol,2-P-2-propanol, T-toluene, MCP-methylcyclopentane, TA - triacetin (glycerin-triacetate). Temperatures are given in ${ }^{\circ} \mathrm{C}$ throughout. All u.v. spectra described in the figures were measured in $10 \mathrm{~mm}$ cells, unless stated otherwise. The concentrations given are those of the solutions at room temperature. The colourless isomer is designated A, and the coloured ones B, C, D.

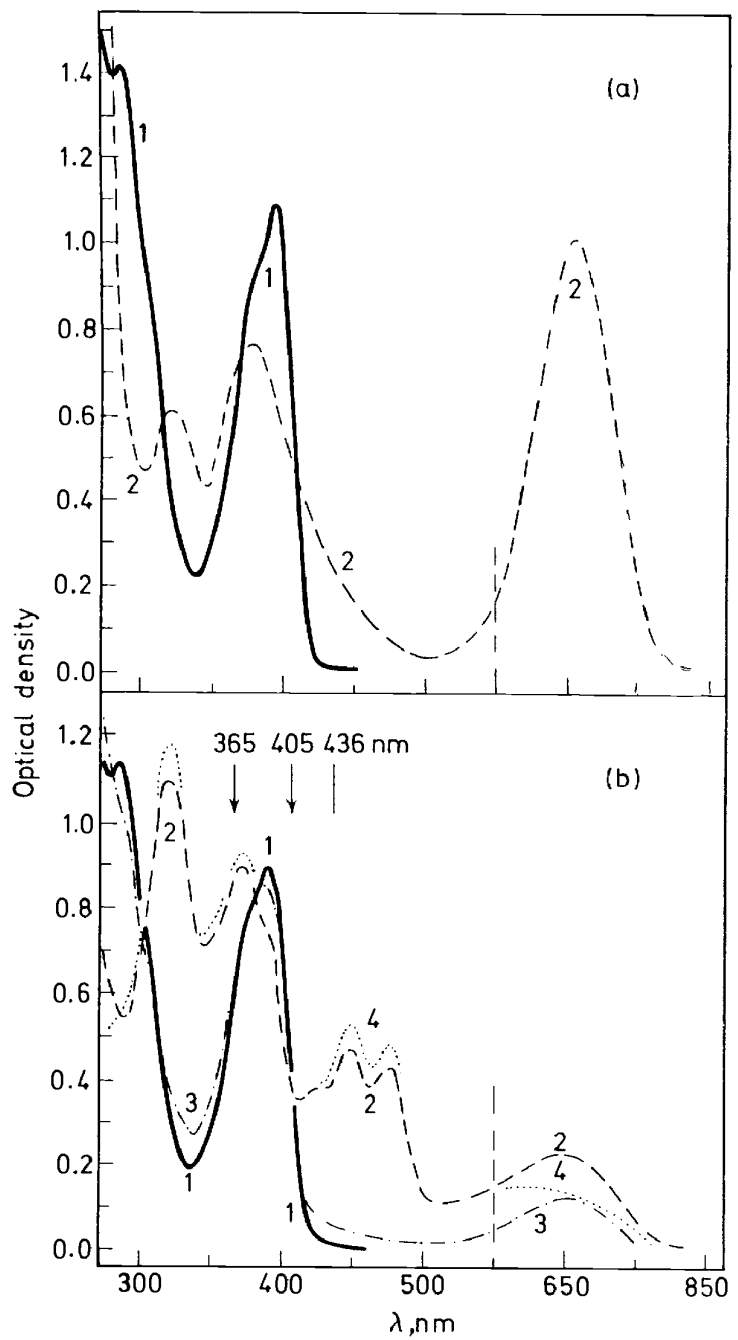

Figure 1. Spectral absorption curves of TMD in MTHF, ca. $5 \times 10^{-5}$ M. (a) at $-160^{\circ}$. Curve 1before irradiation. curve 2-after $405 \mathrm{~nm}$ irradiation 'to completion'. (b) at $-90^{\circ}$. Curve 1 -before irradiation, curve 2 --after $405 \mathrm{~nm}$ irradiation, curve 3--same, followed by $436+546 \mathrm{~nm}$ irradiation, curve 4-calculated for the pure $\mathrm{C}$ isomer. (Note different wavelength scale above and below $550 \mathrm{~nm}$.) 
Reversible photochemistry of the dianthrones in various solvents - stationary methods

The effect of u.v. irradiation (actually including $405 \mathrm{~nm}$ and even $436 \mathrm{~nm}$ ) may be summarized as follows. Starting at the lowest temperatures and highest viscosities, no effect measurable with the recording spectrophotometer was observed (but cf. the 'flash' results described later)! With increasing temperature and decreasing viscosity, a coloured product which peaked in the range $650-730 \mathrm{~nm}$ was formed with an increasing yield [Figure 1(a)]. The results given in Figure 2 for the quantum yield of this photocoloration in TMD are characteristic for all compounds investigated including DA itself. Figures 1 (TMD in MTHF at $-160^{\circ}$ ) and 3 (DA in MTHF at $-175^{\circ}$ ) illustrate

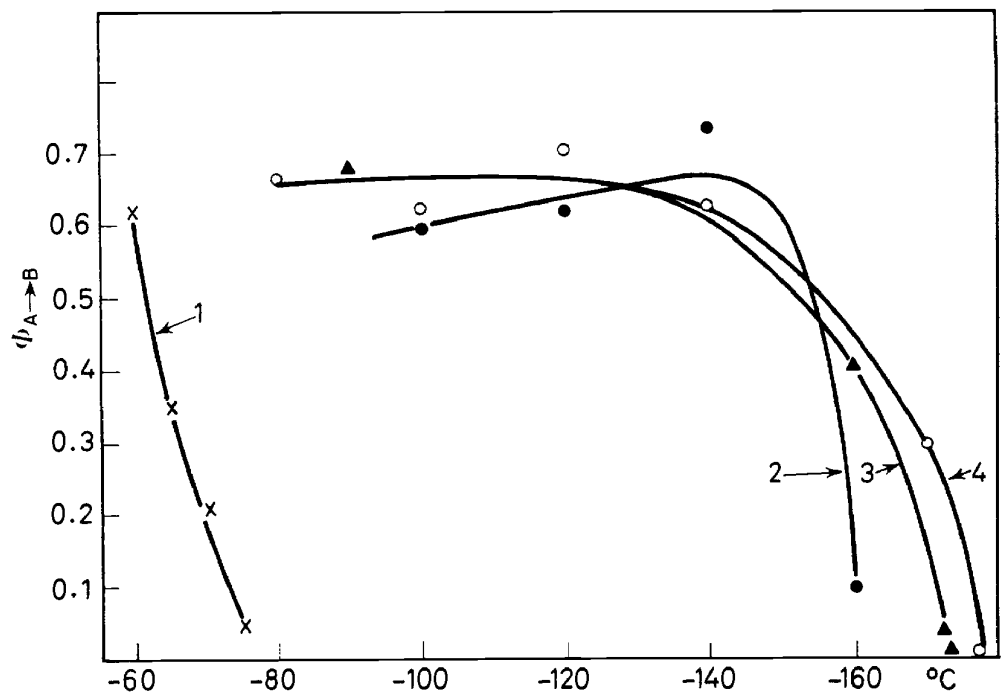

Figure 2. Quantum yields of the reaction $\mathrm{A} \stackrel{\text { h }}{\rightarrow} \mathrm{B}+\mathrm{C}$ at various temperatures, in various solvents : 1-TA, 2-1-P-2-P, 3--MTHF, 4--MCH-2-MP.

the clean results obtained under such conditions, typical for a simple photoconversion A $\stackrel{h y}{\rightarrow} \mathrm{B}$. These changes are completely reversible by heating the solutions to above about $-60^{\circ}$. Irradiation with light absorbed only by the coloured product $\mathrm{B}$ had no effect at any temperature. In the temperature range where the quantum yields of photocoloration are declining sharply, the formation of another isomer, designated D, was observed in DMD and $1,2,1^{\prime}, 2^{\prime}$, -dibenzo-DA ${ }^{16}$, and now in TMD. This isomer is rather similar to the isomer B, which is formed from it thermally at slightly lower vis$\operatorname{cosities}^{16}$, and also directly by irradiation under such conditions ${ }^{16}$. Spectra of $\mathrm{D}$ were given before ${ }^{16}$, and Figure 10(a) shows it for TMD. (Incidentally, this isomer was previously called by us G.) Isomer $\mathrm{D}$ was detected in solutions of TMD in MCH-2-MP, MTHF, 1-P-2-P, MCH-D and TA. Its range of stability is governed solely by the high viscosity of the solvent, as will be detailed later in connection with the 'flash' results. In DA and its 


\section{DIANTHRONE PHOTOCHROMISM 1950-1970}

other derivatives only one coloured isomer was found. We shall assume for the sake of simplicity that it is the B isomer.

At still higher temperatures differences between the various compounds start to appear. In solutions of DA proper, some irreversible reactions start competing with the reversible formation of the B isomer. Figure 3 shows the observations with a solution in MTHF. The abrupt change of the products of irradiation in the temperature region $-175^{\circ}$ to $-150^{\circ}$ is striking. Similar results were obtained with solutions in $\mathrm{MCH}-\mathrm{MCP}, \mathrm{MCH}-\mathrm{T}$, and 1-P-2-P, the respective temperature ranges being about $-180^{\circ}$ to $-160^{\circ},-165^{\circ}$ to $-145^{\circ}$ and $-160^{\circ}$ to $-140^{\circ}$. The nature of some of the irreversible reactions will be described in a separate paragraph.

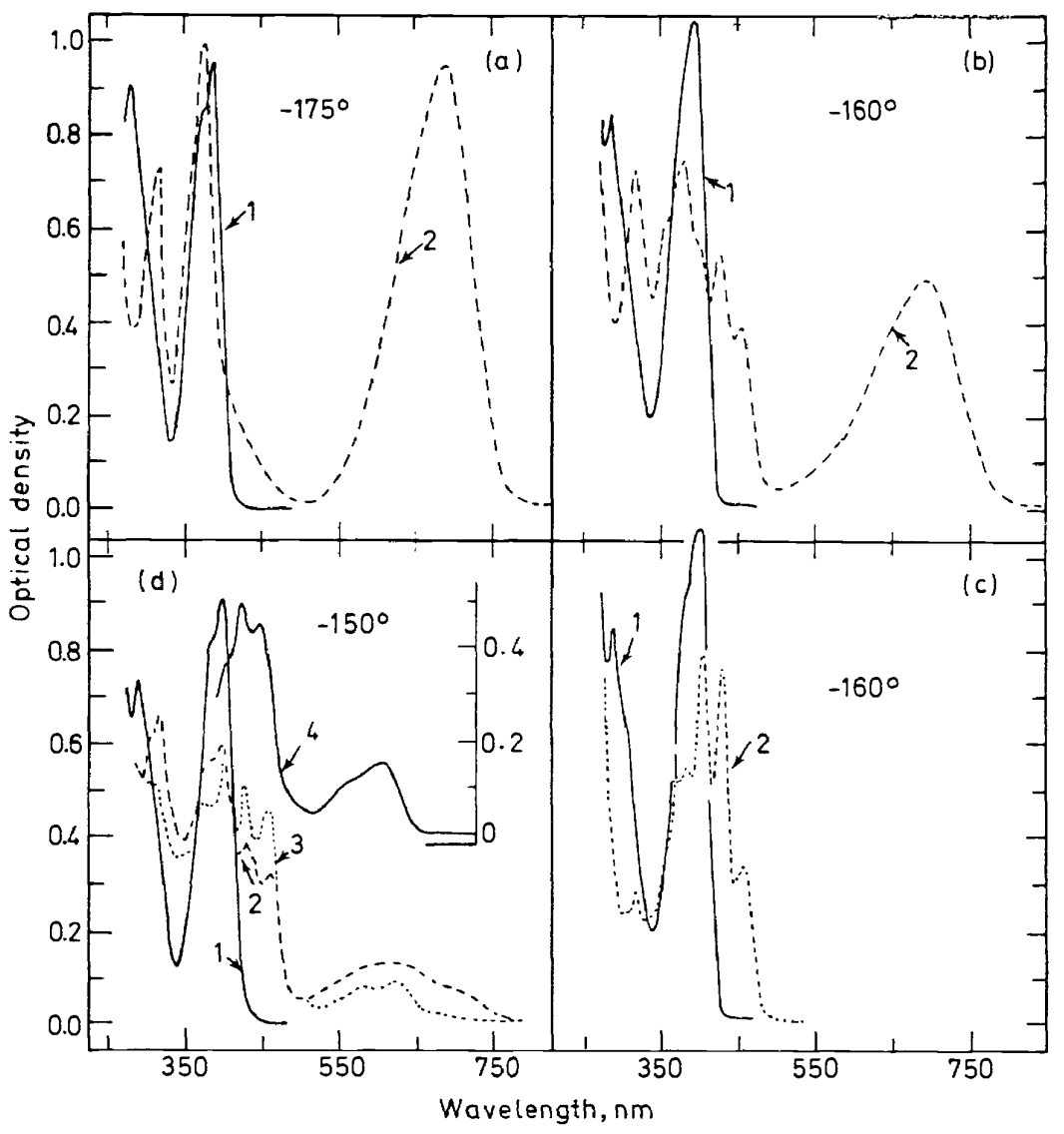

Figure 3. Spectral absorption curves of DA in MTHF, ca. $5 \times 10^{-5}$ M. (a) at $-175^{\circ}$. Curve 1-before irradiation, curve 2--after $405 \mathrm{~nm}$ irradiation 'to completion'. (b) ditto, at $-160^{\circ}$. (c) at $-160^{\circ}$. Curve 1 -before irradiation, curve 2 - solution of curve b2 heated to room temperature and recooled to $-160^{\circ}$. (d) at $-150^{\circ}$. Curve 1 -before irradiation, curve 2 -after $405 \mathrm{~nm}$ irradiation, curve 3-same after $30 \mathrm{~min}$, curve 4 (insert)-same at room temperature. 


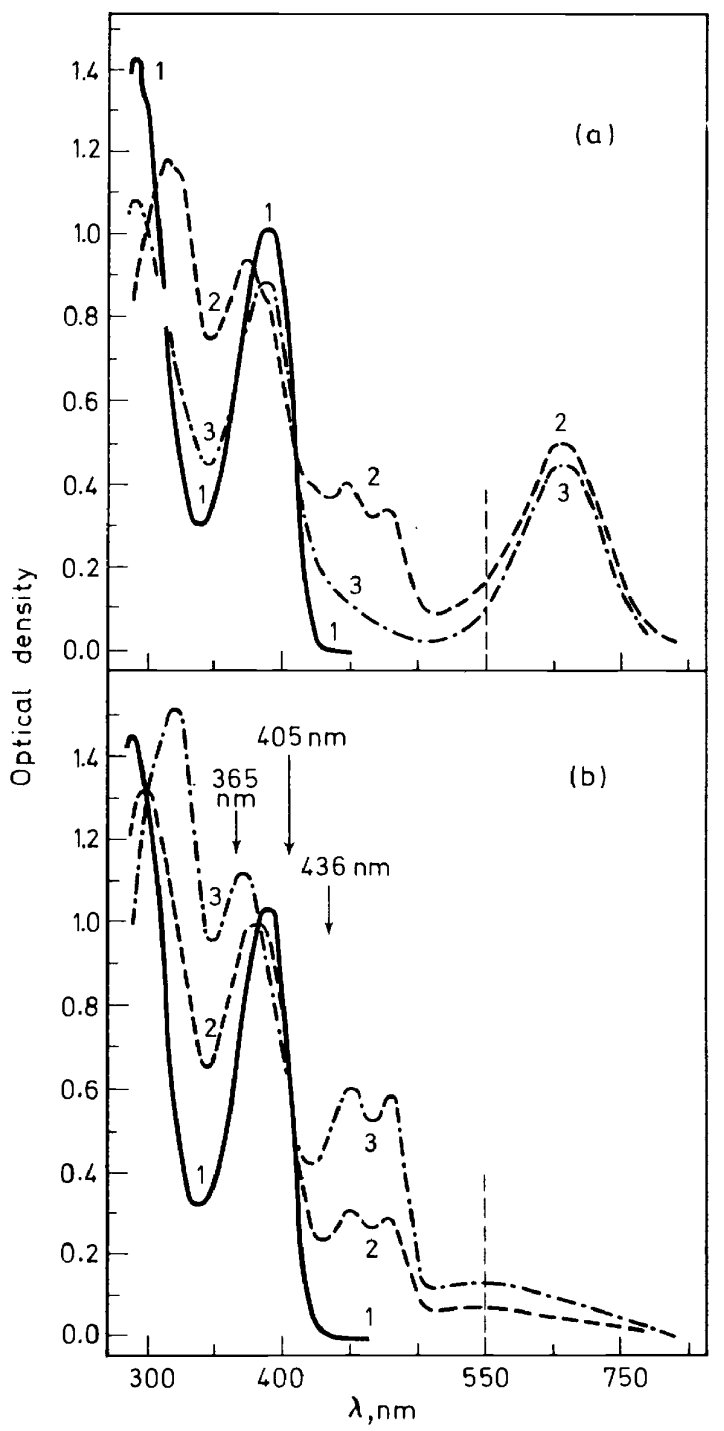

Figure 4. Spectral absorption curves of TMD in toluene, ca. $5 \times 10^{-5} \mathrm{M}$, at $-90^{\circ}$. (a) curve 1-before irradiation, curve 2-after $405 \mathrm{~nm}$ irradiation, curve 3-solution of curve 2, after $546+578 \mathrm{~nm}$ irradiation (erasure of $\mathrm{C}$ isomer). (b) curve 1 -before irradiation, curve 2calculated by adding to curve 1 the difference between curves 2 and 3 in (a), curve 3 -calculated by adding to curve 1 twice the above difference. This should be the absorption of pure $\mathbf{C}$ isomer, - cf. text. (Note different wavelength scales above and below $550 \mathrm{~nm}$.) 
In 1,1'-difluoro-DA irreversible reactions also take place, but to a smaller extent. In 1,1'-dimethoxy-DA and 1,2,1',2'-dibenzo-DA only one isomer is formed at all temperatures, and very little irreversible reactions take place.

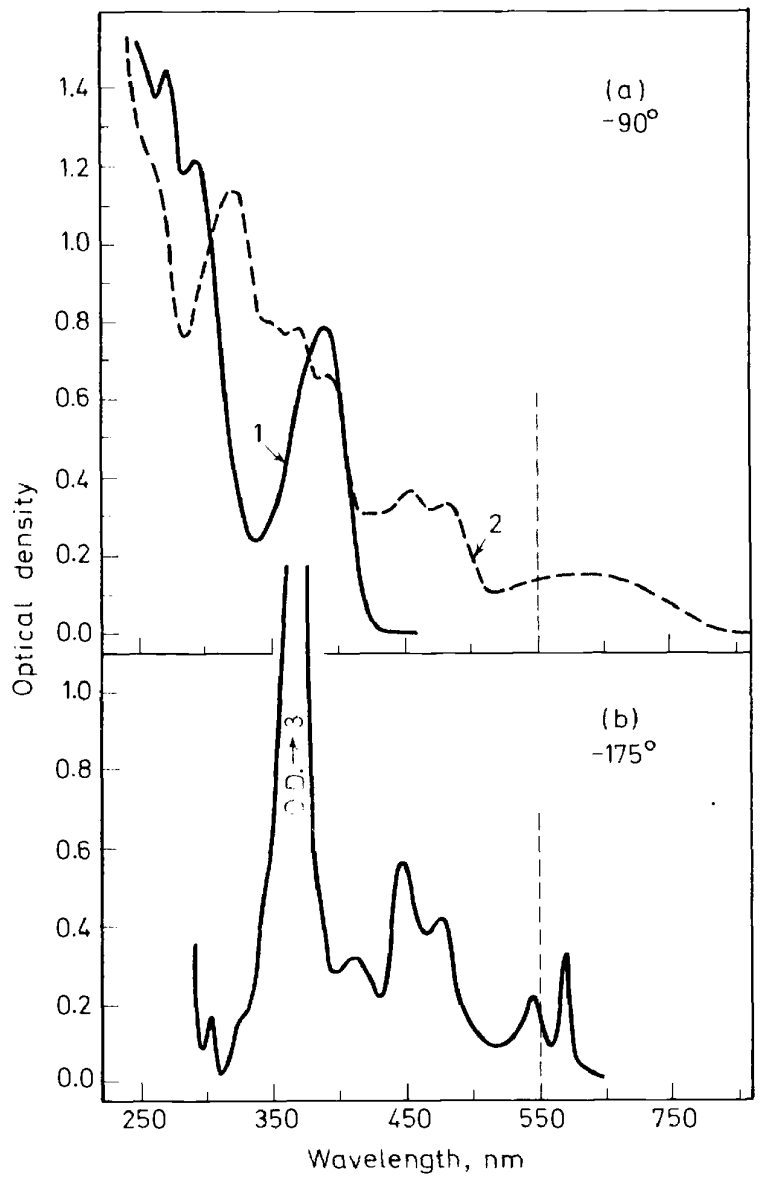

Figure 5. (a): Spectral absorption curve of DMD in $\mathrm{CH}_{2} \mathrm{Cl}_{2}$, ca. $4 \times 10^{-3} \mathrm{M}$, at $-90^{\circ}, 0.1 \mathrm{~mm}$ cell. Curve 1--before irradiation, curve 2-after $405 \mathrm{~nm}$ irradiation 'to completion'. This solution contains about ten per cent starting material and 90 per cent $C$ isomer. Irradiation at $546+578$ $\mathrm{nm}$ regenerates curve 1. (b): Calculated absorption curve of the free radical formed by u.v. irradiation of the B isomer of TMD in MTHF at $-175^{\circ}$ [cf. Figure 1(a)], ca. $4 \times 10^{-4} \mathrm{M}, 1 \mathrm{~mm}$ cell. Calculated by extrapolation from the thermally-reversible change $B \stackrel{h u}{\overrightarrow{4}} \mathbf{R} \cdot$ assuming an actual conversion into $R^{\prime}$ of 15 per cent. (Note different scales above and below $550 \mathrm{~nm}$.)

In DMD and TMD the situation is different. As long ago as $1956 \mathrm{Hirshberg}^{20}$ described a coloured isomer of DMD resulting from u.v. irradiation of solutions in a toluene-alcohol mixture, and partly erasable by irradiation with 'visible' light. This result indicated the existence of more than one thermally reversible coloured isomer. Kortüm ${ }^{14,21}$ described in detail the photoformation of these two coloured isomers of TMD, named by him B and C, and characterized by peaks at around $660 \mathrm{~nm}$ and at $480+450 \mathrm{~nm}$, respectively. 
$\mathrm{B}$ is identical with the $\mathrm{B}$ isomer described above. Kortüm reported that the ratio between the concentrations of the two forms, $[\mathrm{C}] /[\mathrm{B}]$, depends strongly on the nature of the solvent, roughly increasing with solvent polarity. $\mathrm{He}$ also investigated the kinetics of thermal disappearance of both isomers. A comparison with the thermochromic coloured form led to the conclusion that this form is identical with the B isomer obtained by irradiation.

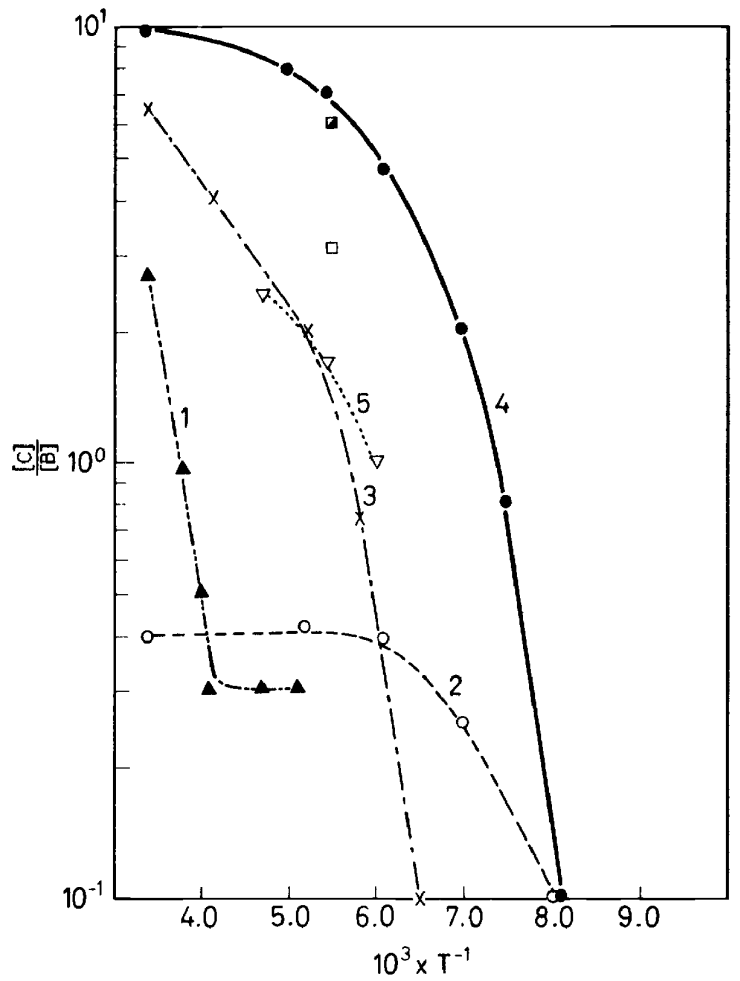

Figure 6. Temperature dependence of the initial ratio $[\mathrm{C}] /[\mathrm{B}]$, following $405 \mathrm{~nm}$ irradiation in various solvents: $1-\mathrm{TA}, 2-\mathrm{MCH}-2-\mathrm{MP}, 3-1-\mathrm{P}-2-\mathrm{P}, 4-\mathrm{MTHF}, 5-\mathrm{CS}_{2}$, $\mathbf{Z}-$-methylene chloride, $\square$-toluene. $\left(T\right.$ denotes ${ }^{\circ} \mathrm{K}$.)

We have observed the $C$ isomer only in DMD and TMD [Figures 1,4,5(a)], and not in any of the other compounds. A thorough study of $\mathrm{C}$ showed that its most characteristic property is its photo-erasability, as distinct from B, and revealed the following. The ratio $[\mathrm{C}] /[\mathrm{B}]$ is a function of the solvent, the temperature, the wavelength of irradiation, and the ratio $[\mathrm{A}] /[\mathrm{C}]$. The first two effects are summarized for TMD in Figure 6, and may serve as an illustration of the temperature dependence of the ratio between two competing reversible photoreactions: $\mathrm{C} \stackrel{k v}{\mathrm{a}} \mathrm{A} \stackrel{h \mathrm{v}}{\longrightarrow} \mathrm{B}$. The dramatic changes in this ratio are mainly a pure temperature effect, since they take place in a temperature region where viscosities are very low. Only triacetin seems to be somewhat exceptional. Figure 7 shows the result of $405 \mathrm{~nm}$ irradiation of a solution of TMD in MTHF. At $-90^{\circ}$ we observe a fast increase in the concentrations of 
$\mathrm{C}$ and $\mathrm{B}$, with $\mathrm{C}$ being the major product. When both curves level off, most of $\mathrm{A}$ has been converted into $\mathrm{B}+\mathrm{C}$. Further irradiation slightly lowers $\mathrm{C}$ and increases B, because of the sequence (1) C $\stackrel{h y}{h} \mathrm{~A},(2) \mathrm{A} \stackrel{h y}{\rightarrow} \mathrm{B}+\mathrm{C}$. This would eventually result in the slow butcompleteconversion of the systeminto thelightstable isomer B. If, however, the temperature is lowered to $-160^{\circ}$ after the levelling-off stage, and the irradiation continued, one observes a rather fast transformation of $C$ into $B$. What actually happens is the sequence (1) $\mathrm{C} \stackrel{h_{y}}{\rightarrow} \mathrm{A},(2) \mathrm{A} \stackrel{h_{\gamma}}{\longrightarrow} \mathrm{B}$, because no $\mathrm{C}$ is formed at this temperature.

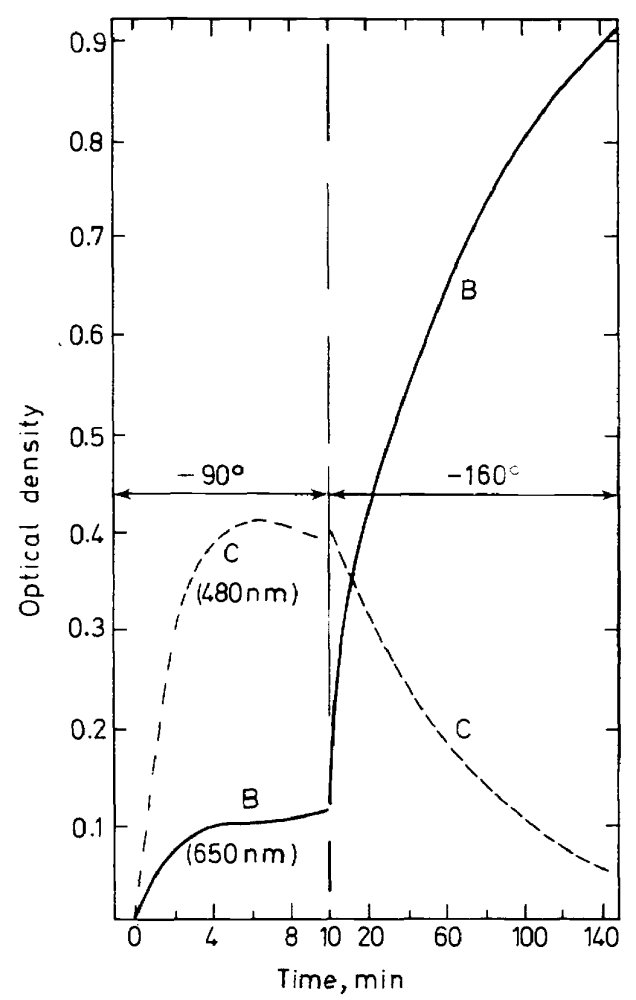

Figure 7. TMD in MTHF, $c a .5 \times 10^{-5} \mathrm{M}$ irradiated at $405 \mathrm{~nm}$. Change of optical density with time of irradiation, measured at the peaks of the $B$ and $C$ isomers (at 660 and $475 \mathrm{~nm}$, respectively). Left part-at $-90^{\circ}$, right part-at $-160^{\circ}$. Note de facto conversion $\mathrm{C} \rightarrow \mathrm{B}$ at $-160^{\circ}$, and ratio of about two between the changes in absorbance at the two wavelengths.

The third and fourth effects are a result of the photoreversibility of the photoreaction A $\stackrel{\text { hv }}{=}$. As in all such reactions ${ }^{22,23}$, the ratio $[\mathrm{C}] /[\mathrm{A}]$ in the product of irradiation during a certain time interval will be larger with light which is more strongly absorbed by A than by C. As shown in Figures 1(b) and 4(b), the C isomer absorbs less than $A$ at $405 \mathrm{~nm}$, while the opposite is true at $365 \mathrm{~nm}$, and even much more so at $436 \mathrm{~nm}$. Indeed the maximal conversion into $C$ was obtained at $405 \mathrm{~nm}$. Since the formation of $B$ is independent of the wavelength, the ratio $[\mathrm{C}] /[\mathrm{B}]$ in the product of irradiation will therefore 
depend on the wavelength in the same way. For the same reason $[C] /[B]$ will be largest when $\mathrm{A}$ is in large excess, i.e. during the early stages of photoconversion. This is so in particular when working with relatively concentrated solutions of $A$, when even very low conversions into $C$ can be detected, such as result from irradiation at $436 \mathrm{~nm}$. The highest extent of conversion into $C$ was observed for DMD in methylene chloride, where virtually only $\mathrm{C}$ is formed.

The absence of the $\mathrm{C}$ isomer in DA and its derivatives not substituted in the 1 and $1^{\prime}$ positions may be due to the above-mentioned irreversible photoreaction taking place at temperatures where $C$ is expected to be formed, e.g. above $-120^{\circ}$ in MTHF. However, for the 1,1'-substituted derivatives this excuse does not hold, and thus the fact remains that at present the $\mathrm{B}$ isomer is observed in all dianthrones, while the $\mathrm{C}$ isomer is peculiar to those derivatives having methyl groups in the 1 and $1^{\prime}$ positions.

The determination of the absorption spectra of the pure coloured isomers, and of the quantum yields of their formation and erasure, will be described in the following paragraphs.

The absorption spectra of $\mathrm{B}$ and $\mathrm{C}$ and the conditions of their formation were found to be independent of the concentration, in the range $5 \times 10^{-3}$ to $10^{-5} \mathrm{M}$.

Finally, it should be noted that even the compounds substituted at the 1 and $i^{\prime}$ positions undergo irreversible reactions on prolonged exposure to u.v.' light. The main product seems to be helianthrone, VII, or one of its derivatives, though the only basis for this assumption is the peak formed irreversibly at around $450 \mathrm{~nm}$. The quantum yields estimated for these processes are $10^{2}$ to $10^{4}$ times smaller than those of the photocoloration, and are highest for $1,1^{\prime}$-difluoro-DA. As shown above for DA itself, irreversible photoreactions are completely suppressed at the lowest temperatures at which photocoloration still takes place.

\section{The absorption spectrum of the $B$ and $D$ isomers}

At sufficiently low temperatures only B is formed on u.v. irradiation of DA and all its derivatives, including TMD. Moreover, no reverse photoconversion into A seems to exist, since the photo-stationary state is independent of the wavelength of irradiation. Thus, for TMD in MTHF at $-160^{\circ}$, Figure 1(a), the same curve 2 is obtained at $436(!), 405$, or $365 \mathrm{~nm}$, despite the large difference in the relative absorptions of B and A. As reported earlier ${ }^{16}$, with DMD identical final curves resulted from irradiation at $254 \mathrm{~nm}$, where B absorbs much more strongly than A, and at $405 \mathrm{~nm}$, where B absorbs less than A [Figure 10(d)]. One may therefore conclude that the curve resulting from irradiation until no further (thermally reversible) changes occur represents the pure $B$ form in all cases investigated. The molar extinction coefficient of the long wavelength peak of $B$ at $650-700 \mathrm{~nm}$ was thus found to be roughly the same as that of the $390-500 \mathrm{~nm}$ peak of A, i.e. about 15000 . As shown earlier ${ }^{16}$, the same holds for the peak at $720-750 \mathrm{~nm}$ characterizing the $D$ isomer. This isomer was detected with DMD ${ }^{16}$, TMD [Figure 10(a)], and 1,2,1', $2^{\prime}-$ dibenzo-DA ${ }^{16}$. The sharp high peak of $B$ at around $260 \mathrm{~nm}$ is noteworthy. For experiments at very low concentrations this peak serves as a preferable indicator of the $\mathrm{B}$ concentration. 


\section{The absorption spectrum of the $C$ isomer}

This isomer was detected only in TMD and DMD. In none of the other derivatives of DA could we form coloured isomers erasable by light in the visible range.

The relative absorption spectrum of $\mathrm{C}$ in the spectral region where $\mathrm{A}$ does not absorb (roughly above $430 \mathrm{~nm}$ ) is the difference between the absorption curves obtained (a) after irradiation at $405 \mathrm{~nm}$, and (b) the same, followed by irradiation with light at wavelengths beyond $450 \mathrm{~nm}$ ('erasure' of C). Such measurements in a variety of solvents, at temperatures where $\mathrm{C}$ is obtained, already show that $C$ is characterized by a double peak at about 450 and 480 $\mathrm{nm}$, and a shoulder or flat peak at longer wavelengths. The position and shape of this part of the spectrum varies widely with the solvent, as seen e.g. for TMD in toluene and in MTHF in Figures 1(b) and 4(b). The ratio between the absorbances of $C$ at the $480 \mathrm{~nm}$ peak and at $660 \mathrm{~nm}$ (the wavelength of the B peak), in several solvents, is as follows: Toluene--6.5, MTHF--4.5, $\mathrm{CH}_{2} \mathrm{Cl}_{2}-3, \mathrm{MCH}--5,1-\mathrm{P}-2-\mathrm{P}--3.3, \mathrm{CHCl}_{3}-2.5$. For DMD in $\mathrm{CH}_{2} \mathrm{Cl}_{2}$ it is 2.8 [Figure $5(\mathrm{a})$ ].

In order to obtain or at least estimate the absolute absorption spectrum of $C$ in the visible and the u.v., one has to know what fraction of $A$ has been converted into $C$ by irradiation at $405 \mathrm{~nm}$. We shall denote this fraction by $\beta$, and assume for the moment that it can be estimated. If no B is formed under these conditions, we obtain the absorbance of $\mathrm{C}$ at each wavelength by adding to the absorbance of pure A the difference between curves (a) and (b) above, divided by $\beta$. If B is also formed, as illustrated in Figures I(b) and 4(a), let us denote its fraction by $\alpha$. The absorbance $D$ of the solution at any wavelength, following $405 \mathrm{~nm}$ irradiation [curves 2 in Figures 1(b) and 4(a) will be

$$
D=D_{\mathrm{A}}(1-\alpha-\beta)+D_{\mathrm{B}} \alpha+D_{\mathrm{C}} \beta
$$

where $D_{\mathrm{A}}, D_{\mathrm{B}}, D_{\mathrm{C}}$ denote the absorbance of pure $\mathrm{A}, \mathrm{B}, \mathrm{C}$ under the experimental conditions. Following erasure of $C$, i.e. reconversion into $A$ (curves 3 ),

$$
D=D_{\mathrm{A}}(1-\alpha)+D_{\mathrm{B}} \alpha
$$

The difference between equations 1 and 2 is $\beta\left(D_{\mathrm{C}}-D_{\mathrm{A}}\right)$. To obtain $D_{\mathrm{C}}$ we divide this difference by $\beta$ and add it to $D_{\mathrm{A}}$. In Figure $4(\mathrm{~b})$ this was done for two values of $\beta: 1.0$ in curve 2 and 0.5 in curve 3 (the correct one). If no $B$ is formed, $\alpha=0$ in equations 1 and 2 . In this case the experimental curve obtained after $405 \mathrm{~nm}$ irradiation is just $D=D_{\mathrm{A}}(1-\beta)+D_{\mathrm{c}} \beta$, and the procedure given above is an extrapolation of the observed change to 100 per cent conversion into $C$. Similar measurements in $1 P-2 P$ were extended to $220 \mathrm{~nm}$ [Figure 10(d)]. In order to estimate $\beta$ it is essential to find a correlation between the absorption coefficients of the unknown $C$ and the known A or B forms. Such a correlation is possible if there exists a spectral region where only the known and not the unknown isomer absorbs. This is true regarding $\mathbf{B}$ at long wavelengths, where the absorption of $\mathrm{C}$ is either very low, or else a well-defined fraction of its absorption at $480 \mathrm{~nm}$, where neither A nor B absorbs. We therefore made use of the de facto conversion of $C$ into $B$ via $A$, by first irradiating $A$ at $405 \mathrm{~nm}$ until further spectral 
changes were small (i.e. virtually complete conversion $A \stackrel{\text { hv }}{\rightarrow} B+C$ ), and then irradiating alternately at $546+578 \mathrm{~nm}$ and at $405 \mathrm{~nm}$, until almost all C was converted into $B$ :

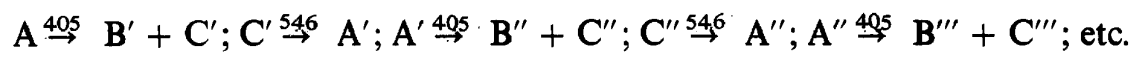
$C^{\prime} \equiv B^{\prime \prime}+B^{\prime \prime \prime}+B^{\prime \prime \prime \prime}+\ldots$, i.e. the total increment in $B$ is equivalent to the quantity of $C$ which disappeared. The above sequence is illustrated in Figure 8 for a solution in toluene. The conclusion is that the absorbance $D$ of $C$ at $480 \mathrm{~nm}$ is roughly half that of $B$ at $660 \mathrm{~nm}$, which in turn is about equal to that of $\mathbf{A}$ at $395 \mathrm{~nm}$. The absorption curves calculated for pure $\mathbf{C}$ in Figures 1 (b) and $4(\mathrm{~b})$, as well as calculations of quantum yields, are based on the above conclusion, i.e. $D_{485}^{\mathrm{C}} \approx 0.5 \times D_{395}^{\mathrm{A}}$.

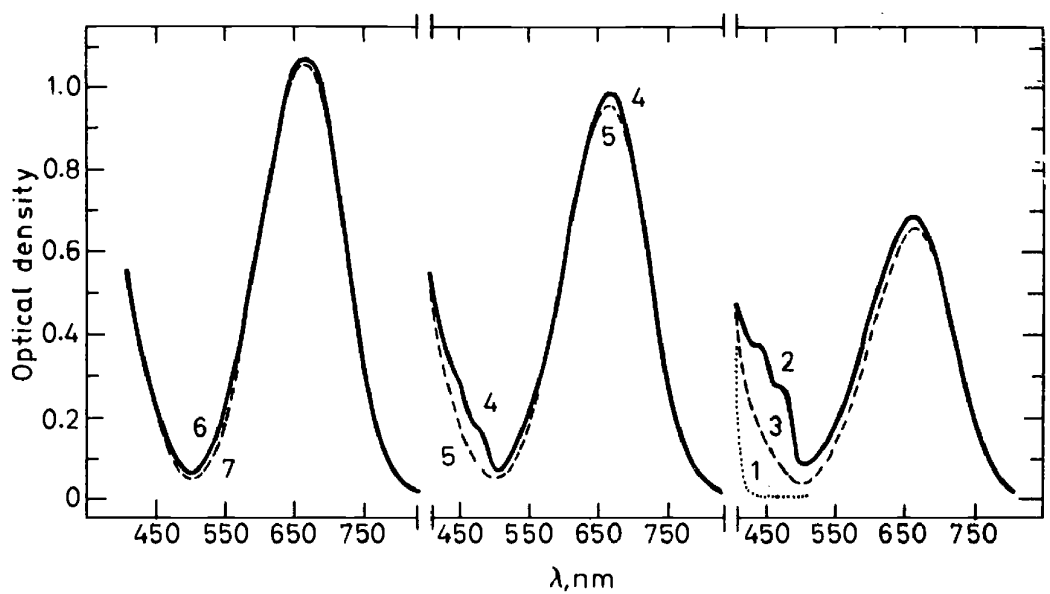

Figure 8. Absorption spectra of TMD in toluene at $-90^{\circ}$, showing stepwise conversion of $\mathrm{C}$ into B. Curve 1-before irradiation; curve 2-after $405 \mathrm{~nm}$ irradiation until the peak at $480 \mathrm{~nm}$ starts to fall; curve 3-same, after $546+578 \mathrm{~nm}$ irradiation, to erase $\mathrm{B}$; curves $4-7$-after alternate irradiations as above.

The case of DMD in methylene chloride is unique since almost only the C isomer is formed by $405 \mathrm{~nm}$ irradiation, and the system is therefore completely photoreversible. Since the quantum yield of the reverse reaction is small (cf. later), it is possible to convert about 90 per cent of the compound into its $\mathrm{C}$ isomer [curve 2 in Figure 5(a)] and therefore the experimental curve represents the absorption of almost pure $\mathbf{C}$.

Superficially the absorption spectra of $\mathrm{B}$ and $\mathrm{C}$ are very different, but the positions of the peaks are actually rather similar, as shown in the following comparison for TMD in MTHF [Figure l(b)], and in $\mathrm{CH}_{2} \mathrm{Cl}_{2}$.

B : 670, (submerged bands), 370, 325, 265.

C: (600), 480, 445, (390), 370, 320 (in MTHF).

$630,480,455,390,370,350,320$ (in $\mathrm{CH}_{2} \mathrm{Cl}_{2}$ ). 


\section{Quantum yields of photocoloration and photo-erasure}

A calculation of absolute quantum yields of the reactions $\mathrm{A} \stackrel{\text { hv }}{\rightarrow} \mathrm{B}+\mathrm{C}$ and $\mathrm{C} \stackrel{\text { hv }}{\rightarrow} \mathrm{A}$ necessitates information about the molar extinction coefficients of A, B and C. Using the estimates for $\mathbf{B}$ and $\mathbf{C}$ given in the preceding paragraph and applying Zimmerman's method ${ }^{22,23}$, we arrived at the yields shown in Figure 2 for TMD in various solvents. The yields for other derivatives were of the same order of magnitude. For DMD in methylene chloride, where we have a pure $\mathrm{A} \stackrel{h w}{=} \mathrm{C}$ photo-interconversion, the yields at $-90^{\circ}$ were $\Phi_{\mathrm{A} \rightarrow \mathrm{C}}$ $=0.5$ at $405 \mathrm{~nm}$ and $\Phi_{\mathrm{C} \rightarrow \mathrm{A}}=0.06$ at $436 \mathrm{~nm}$.

The quantum yield of the reaction $\mathrm{C} \stackrel{\text { hr }}{\rightarrow} \mathrm{A}$ at 436 and $546 \mathrm{~nm}$ was also measured in a wide temperature range. The yields for TMD in MTHF were as follows : 0.05 at $-90^{\circ}, 0.04$ at $-120^{\circ}, 0.03$ at $-150^{\circ}, 0.02$ at $-180^{\circ}$. These values are thus all low, but little affected by low temperatures and high viscosities. In contrast, the yields of the photocoloration (Figure 2) are around 0.6 but drop to zero at $-175^{\circ}$.

The yields observed for $\mathrm{A} \rightarrow \mathrm{B}+\mathrm{C}$ in TMD should be compared with the fluorescence quantum yields $\Phi_{F}$ described in one ${ }_{*}$ of the following paragraphs. Obviously the sum of the overall yields for $\mathrm{A} \stackrel{h \gamma}{\rightarrow} \mathrm{A} \rightarrow \mathrm{A}$ and $\mathrm{A} \stackrel{\text { hy }}{\rightarrow} \mathrm{A} \rightarrow \mathrm{B}+\mathrm{C}$, irrespective of possible intermediates, cannot exceed unity. The actual numbers show that this sum indeed approaches unity in several cases. Thus for TMD in MTHF at $-150^{\circ}, \Phi_{\mathrm{F}}=0.4$ and $\Phi_{\mathrm{A} \rightarrow \mathrm{B}}=0.55$; for TMD in $\mathrm{MCH}-2-\mathrm{MP}$ at $-120^{\circ}, \Phi_{\mathrm{F}}=0.25, \Phi_{\mathrm{A} \rightarrow \mathrm{B}}=0.70$; for DMD in MCH-2-MP at $-160^{\circ}, \Phi_{\mathrm{F}}=0.1, \Phi_{\mathrm{A} \rightarrow \mathrm{B}}=0.9$. Therefore, as long as the viscosity is not high enough to lower the photocoloration yield, excited $\AA \grave{\AA}$ molecules either fluoresce or cross over into B, as shown in detail in the following paragraph.

\section{Flash spectroscopic results, triplet $A$, and its involvement in the formation of the coloured isomers $D$ and $B$}

Flash experiments with TMD reported by Kortüm ${ }^{24}$ and by Günthard ${ }^{25}$ and co-workers indicated the existence of a long-lived intermediate absorbing at around $490 \mathrm{~nm}$ and emitting a red phosphorescence.

We investigated the flash photolysis of TMD in a variety of solvents and in a wide temperature range, from $-186^{\circ}$ upwards. In addition, less detailed measurements were made with DA proper, and its $1,1^{\prime}$-dimethyl, -difluoro, -dimethoxy and 1,2,1',2'-dibenzo derivatives. In all cases we observed a transient roughly similar to the one described before, characterized by a peak in the range $460-490 \mathrm{~nm}$. At somewhat higher temperatures this transient, instead of returning to the starting material, was in all cases converted into a coloured modification. Before describing this interconversion in detail, we mention that with TMD the decay of this transient absorbing at $490 \mathrm{~nm}$ parallels that of the emission at $600 \mathrm{~nm}$. Moreover, e.s.r. measurements at constant illumination show a typical triplet signal at a peak field of 1528 gauss. Kinetic measurements on this signal, following a light flash in the e.s.r. cavity, gave decay curves similar to those obtained for either the $490 \mathrm{~nm}$ absorption or the $600 \mathrm{~nm}$ emission (Figure 9). The identification of the intermediate as a triplet may thus be taken as proven. The absorption spectrum of the triplet ${ }^{3} \mathrm{~A}$ is given in curve $X$ in Figure 10(a). The broad and low band above $550 \mathrm{~nm}$ is noteworthy. The molar extinction coefficient at the 


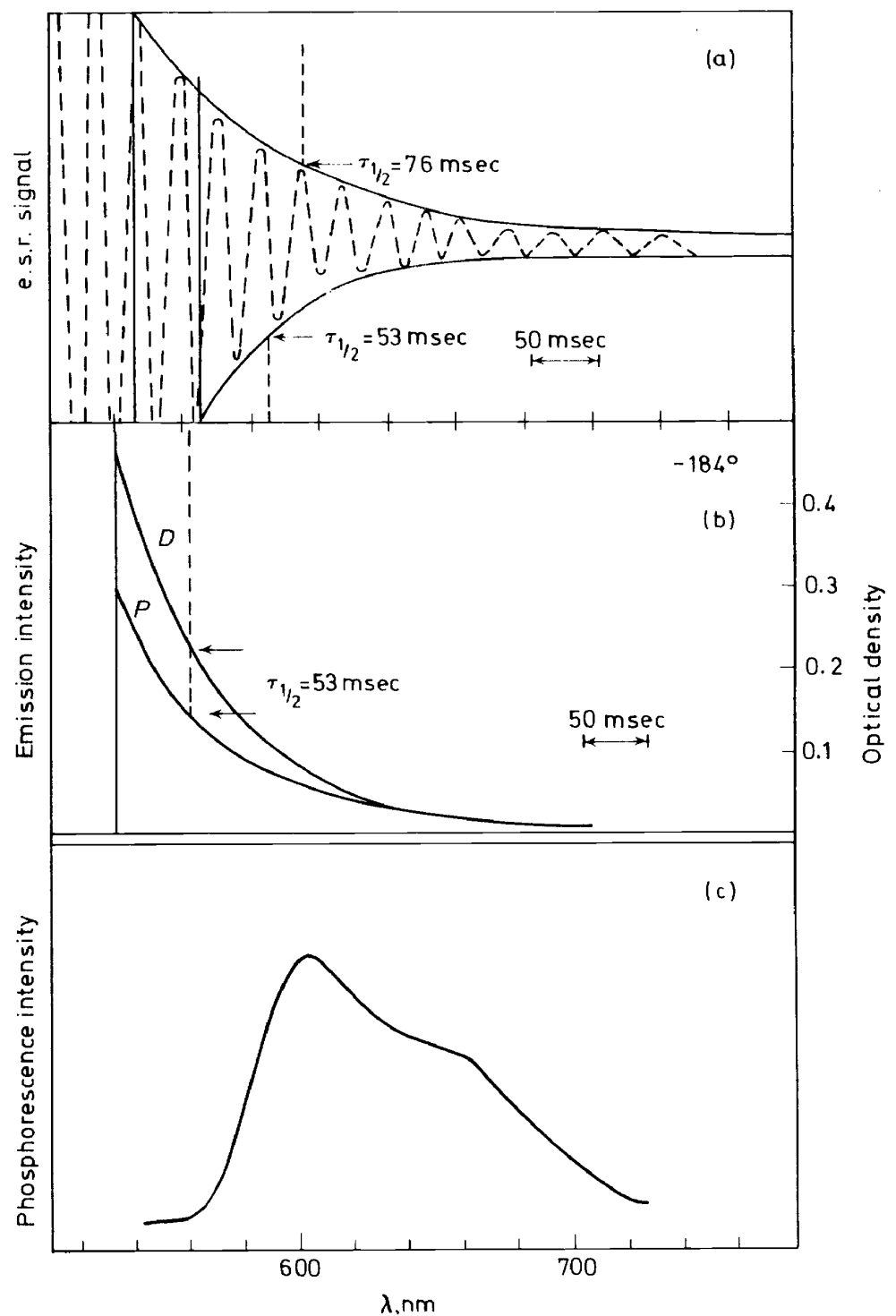

Figure 9. TMD in MCH-2-MP at $-186^{\circ}$. (a) decay of e.s.r. signal at 1525 gauss following flash excitation. (b) Decay of phosphorescence intensity $(P)$ and absorbance at $490 \mathrm{~nm}(D)$. (c) Phosphorescence spectrum of the colourless modification. 


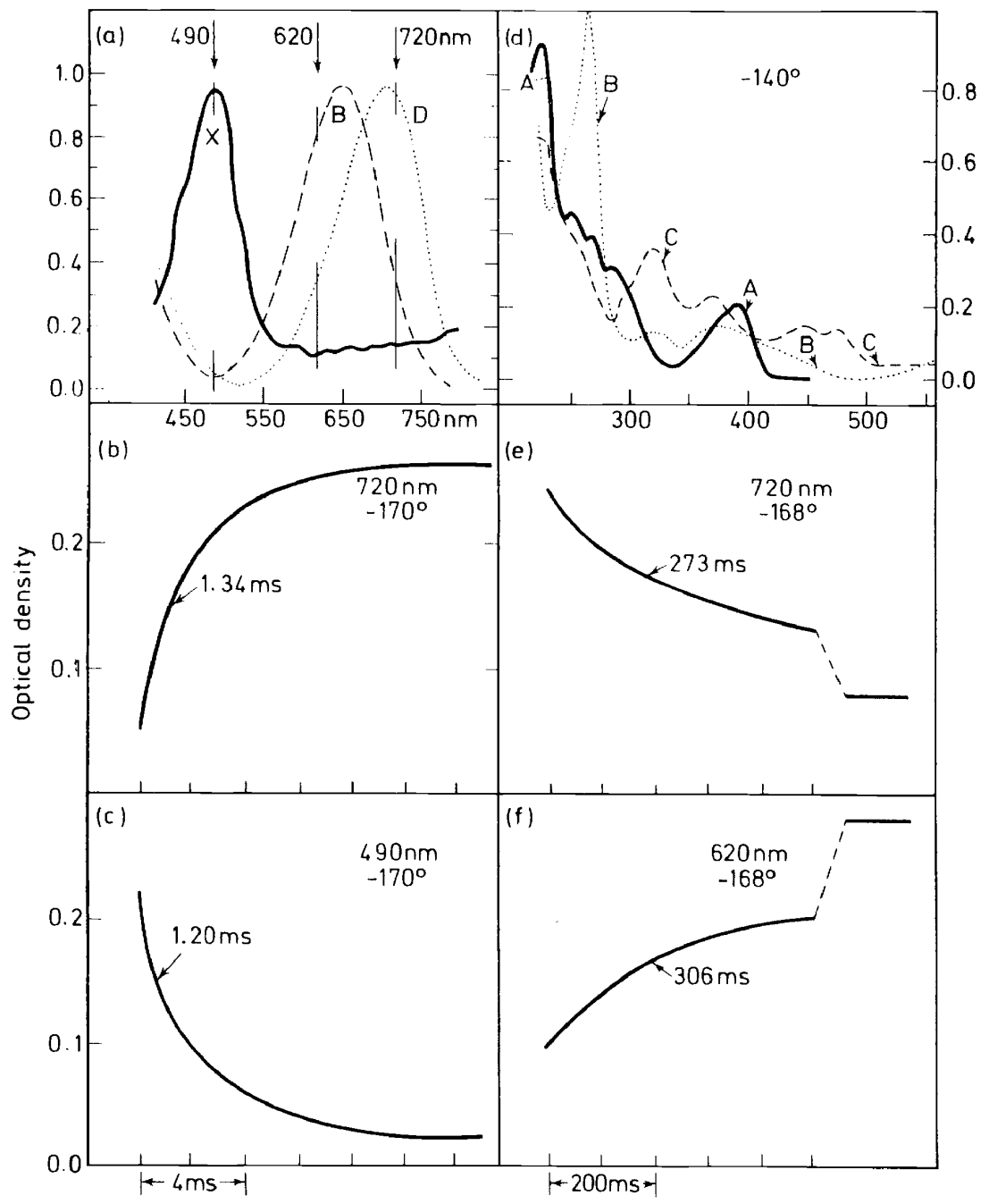

Figure 10. (a): Absorption spectra of suggested triplet $(X)$, from flash experiments with TMD in MCH-2-MP at $-180^{\circ}$, and of $\mathrm{D}$ and $\mathrm{B}$ isomers. Optimal wavelengths for measuring the concentrations of X, D and B are marked by arrows. Note spectral overlap! (b), (c), (e), (f): Changes of optical density with time at the wavelengths and temperatures indicated, following flash excitation. (d): Absorption spectra of a $10^{-5} \mathrm{M}$ solution of TMD in 1-P-2-P at $-140^{\circ}$. for the pure A, B and C isomers (curve $\mathrm{C}$ is extrapolated). 
T. BERCOVICI, R. KORENSTEIN, K. A. MUSZKAT and E. FISCHER

peak is estimated as about equal to that of $B$ at its peak. The formation and the first order disappearance of the $490 \mathrm{~nm}$ peak were measured in a wide range of temperatures. The extent of formation was found to be the same at all temperatures. Figure 10(c) shows the decay of the absorption at $490 \mathrm{~nm}$. From similar curves at various temperatures we arrived at the temperature dependence of the rate constants of triplet disappearance.

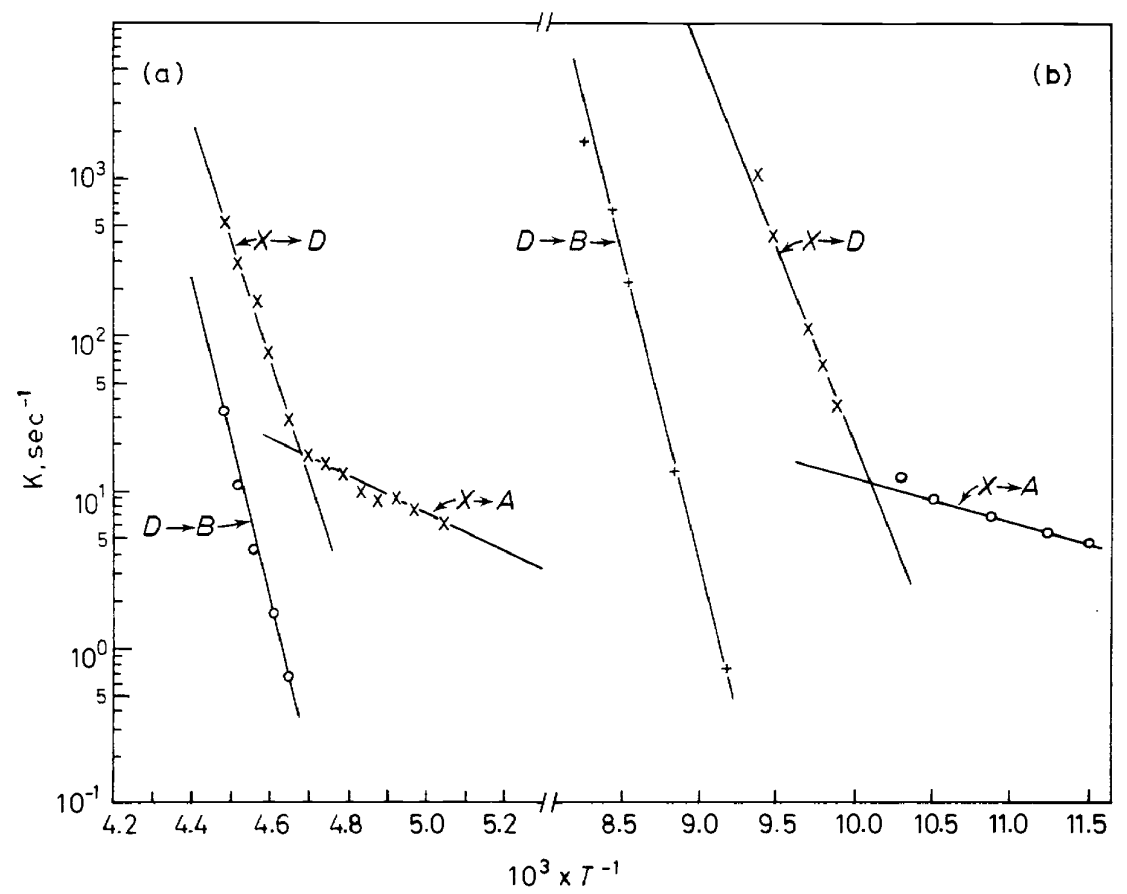

Figure 11. TMD in various solvents. Temperature dependence of the first order rate constants of the triplet decay $(X \rightarrow A, X \rightarrow D)$ and the transformation $D \rightarrow B$. Arrhenius critical increments in Table 1 were calculated from these and similar curves. (a)-in TA, (b)-in MCH-2-MP. (T denotes ${ }^{\circ} \mathrm{K}$.)

The results obtained for TMD in two solvents of widely different viscosity are described in Figure 11 in the form of Arrhenius curves. The special feature of these 'curves' is the weak temperature dependence in the range of temperatures where no photocoloration takes place (low quantum yields, cf. Figure 2) as against the pronounced temperature dependence at higher temperatures. Table 1 summarizes the Arrhenius critical increments, observed in three solvents, together with the temperature and viscosity at the 'break' point. This value gives some indication of the viscosities needed to affect the triplet $\rightarrow \mathrm{D}$ process. In similar experiments in a $\mathrm{MCH}$-decalin mixture the break point was at about $-155^{\circ}$. The temperature dependence in the high-temperature region is obviously a viscosity effect. This is also borne out by the parallelism between the critical increments, $E_{a}$, of the viscosity $\eta$ (when plotted as $\log \eta$ versus $T^{-1}$ ) and those of the disappearance of the triplet peak. 


\section{DIANTHRONE PHOTOCHROMISM 1950-1970}

A detailed spectral analysis showed that in the temperature range of fast triplet disappearance a new band peaked at about $720 \mathrm{~nm}$ is formed, parallel to the disappearance of the $490 \mathrm{~nm}$ band. Figures $10(\mathrm{~b})$ and $10(\mathrm{c})$ show the kinetics at $-170^{\circ}$. The new band is shown as curve $D$ in Figure $10(a)$ and actually describes the $\mathrm{D}$ isomer reported earlier ${ }^{16}$ for $1,2,1^{\prime}, 2^{\prime}$-dibenzo-DA and for DMD. The kinetic curves may serve as convincing evidence for the formation of $D$ via the triplet.

Table 1. Activation energies of the reactions ${ }_{1}^{3} \mathrm{~A} \rightarrow{ }_{0}^{1} \mathrm{~A} ;{ }_{1}^{3} \mathrm{~A} \rightarrow \mathrm{D} ; \mathrm{D} \rightarrow \mathrm{B}$; for TMD in various solvents. $E_{\mathrm{vis}}$ is the 'activation energy' of the solvent viscosity in the same temperature region. Values in $\mathrm{kcal} / \mathrm{mole}( \pm 0.5)$. The temperature of the 'break point', and the viscosity at this temperature, are given in the last columns (cf. Figure 11).

\begin{tabular}{|c|c|c|c|c|c|c|}
\hline \multirow[b]{2}{*}{ Solvent } & \multirow[b]{2}{*}{${ }_{1}^{3} \mathrm{~A} \rightarrow{ }_{0}^{1} \mathrm{~A}$} & \multirow[b]{2}{*}{${ }_{1}^{3} \mathrm{~A} \rightarrow \mathrm{D}$} & \multirow[b]{2}{*}{$\mathrm{D} \rightarrow \mathrm{B}$} & \multirow[b]{2}{*}{$E_{\mathrm{vis}}^{a, b}$} & \multicolumn{2}{|c|}{ 'Break point' } \\
\hline & & & & & $\underset{{ }^{\circ} \mathrm{C}}{\text { Temp. }}$ & $\begin{array}{l}\text { Viscosityc } \\
\log (\mathrm{cP})\end{array}$ \\
\hline TA & 5 & 36 & 47 & 46 & -59 & 8.8 \\
\hline MTHF & 1.5 & 16 & 16 & 23 & -166 & 7.5 \\
\hline MCH-2-MP & 1.3 & 11.5 & $(18.5)$ & 13 & -174 & 7.3 \\
\hline
\end{tabular}

${ }^{(a)}$ Ref. $26{ }^{(b)}$ Ref. $27{ }^{(c)}$ extrapolated from our measurements ${ }^{26}$

The kinetic curves taken on a much longer time scale show [Figures 10(e), $10(\mathrm{f})]$ that now the peak at $720 \mathrm{~nm}$ disappears, and at the same time a peak at $650 \mathrm{~nm}$ rises. The latter peak is stable at these temperatures, and characterizes the B isomer described above. These kinetic curves in fact describe the transformation D $\rightarrow$ B briefly reported earlier ${ }^{16}$. The kinetics of this transformation were followed in a range of temperatures. The resulting Arrhenius plots in two solvents are shown in the left-hand lines in Figures 11(a) and 11(b). The corresponding activation energies are summarized in the $\mathrm{D} \rightarrow \mathrm{B}$ column of Table 1 . The thermal transformation $\mathrm{D} \rightarrow \mathrm{B}$, just like the ${ }^{3} \mathrm{~A}^{*} \rightarrow \mathrm{D}$ process described above, is clearly a viscosity-controlled process. This confirms our earlier results with static methods, where the range of thermal stability of $D$ was found to move to higher temperatures when a $\mathrm{MCH}$-decalin mixture was used. Its viscosity at about $-160^{\circ}$ equals that of a MCH-2-MP mixture at $-180^{\circ}$.

The results of the flash experiments may be correlated with the results obtained with static methods, described in previous paragraphs, by postulating the following sequence:

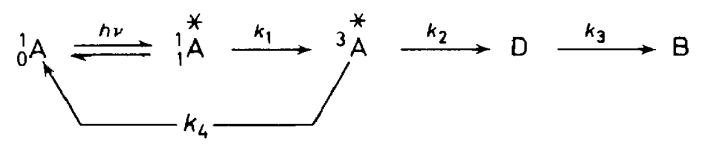

The four thermal processes $k_{1}-k_{4}$ differ in their dependence on the viscosity. $k_{1}$ and $k_{4}$ are little affected (although the critical increment of $5 \mathrm{kcal} / \mathrm{mole}$ in triacetin indicates some effect), while $k_{3}$ and then $k_{2}$ decrease sharply at higher viscosities, in the range of $10^{7}$ to $10^{9} \mathrm{cP}$. As a result, the extent of 
triplet formation is roughly the same at all temperatures, but with decreasing viscosity an increasing fraction is converted into $\mathrm{D}$. As with stationary methods above, the separate existence of $\mathrm{D}$ and $\mathrm{B}$ isomers was observed by flash methods only with DMD, TMD and 1,2,1',2'-dibenzo-DA, in alcohols, MTHF, MCH-2-MP or MCH-decalin. In DA and its derivatives only one coloured isomer was observed as being formed via the triplet. Whether it is the analogue of $\mathrm{D}$ or $\mathrm{B}$ in the three above compounds could not be ascertained.

The $\mathrm{C}$ isomer described above is formed in substantial concentrations only at higher temperatures (Figure 6), when the triplet is too short-lived to be observed under our conditions. Moreover, the absorption spectra of $\mathrm{C}$ and the triplet are somewhat similar. It is therefore impossible to show whether or not $\mathrm{C}$ is also formed via the triplet. Most recent results obtained by $\mathbf{C}$. $\mathbf{R}$. Goldschmidt, Jerusalem, show that the $\mathrm{C}$ isomer of DMD in $\mathrm{CH}_{2} \mathrm{Cl}_{2}$ is formed within 50 nanoseconds at room temperature, following a $10 \mathrm{~ns}$ flash $^{39}$.

The above results show that at low temperatures the B isomer is formed via triplet $\mathrm{A}$ and the $\mathrm{D}$ isomer. The conclusion that the same mechanism operates at higher temperatures is plausible but not obvious, and a mixed singlettriplet mechanism may well operate. In this context one should mention Dombrowski's unpublished results in which he showed that the formation of B can be sensitized by biacetyl ${ }^{2}$. The irreversible photoreactions almost certainly do not start from the triplet state.

\section{Fluorescence of the non-coloured isomer (A)}

Kortüm ${ }^{21}$ reported a pronounced shift of the emission peak of TMD to the blue when the viscosity of the solution is increased. We could confirm these results in a variety of solvents, including aliphatic hydrocarbons, for DMD, TMD and 3,3'-DMD, but not for DA itself. Figure 12(a) shows a typical case. The emission curves were recorded at varying sensitivity, in order to bring all curves to the same peak height. The blue shift in any particular solvent is confined to a limited temperature range. The results obtained in various solvents are summarized in Table 2, in which we also give for each solvent the temperature and viscosity at three points; the onset, the midpoint, and the endpoint of the shift. The shift is described by the wavelength at which the emission reaches half its peak height going downwards in wavelength [cf. Figure 12(a)]. The viscosities were taken from own measurements ${ }^{26}$ or from those of Labhart ${ }^{27}$.

The quantum yield of fluorescence was measured as a function of temperature in the same solvents, with diphenylhexatriene $\left(\Phi_{\mathrm{F}}=0.78\right)$ and 9,10diphenylanthracene $\left(\Phi_{F}=1.0\right)$ serving as reference compounds ${ }^{28}$.

The results for TMD are given in Figure 12(b), and show that $\Phi_{\mathrm{F}}$ passes through a maximum, roughly parallel to the midpoint of the blue shift. The temperature of maximal fluorescence yields and the respective viscosity are given below the solvent name in Table 2. Similar experiments with solutions of the reference compounds showed no temperature effect. The excitation and the absorption spectra of TMD are practically identical at all temperatures. DMD shows a similar effect, and the values of $\Phi_{F}$ at various temperatures, measured with a solution in MCH-2-MP excited at $330 \mathrm{~nm}$. were : 0.015 


\section{DIANTHRONE PHOTOCHROMISM 1950-1970}

$\left(-100^{\circ}\right), 0.065\left(-144^{\circ}\right), 0.10\left(-158^{\circ}\right), 0.08\left(-180^{\circ}\right), 0.07\left(-190^{\circ}\right)$. Again a solution of DA itself in MCH-2-MP showed no comparable effect (in view of the photosensitivity of DA and its derivatives, all emission measurements were carried out under conditions where a minimum of exciting light hit the solutions, i.e. narrow slits on the excitation monochromator, fast scanning, high sensitivity of the detector.) The yields were: $0.02\left(-90^{\circ}\right), 0.06\left(-130^{\circ}\right)$, $0.09\left(-170^{\circ}\right), 0.1\left(-186^{\circ}\right)$.

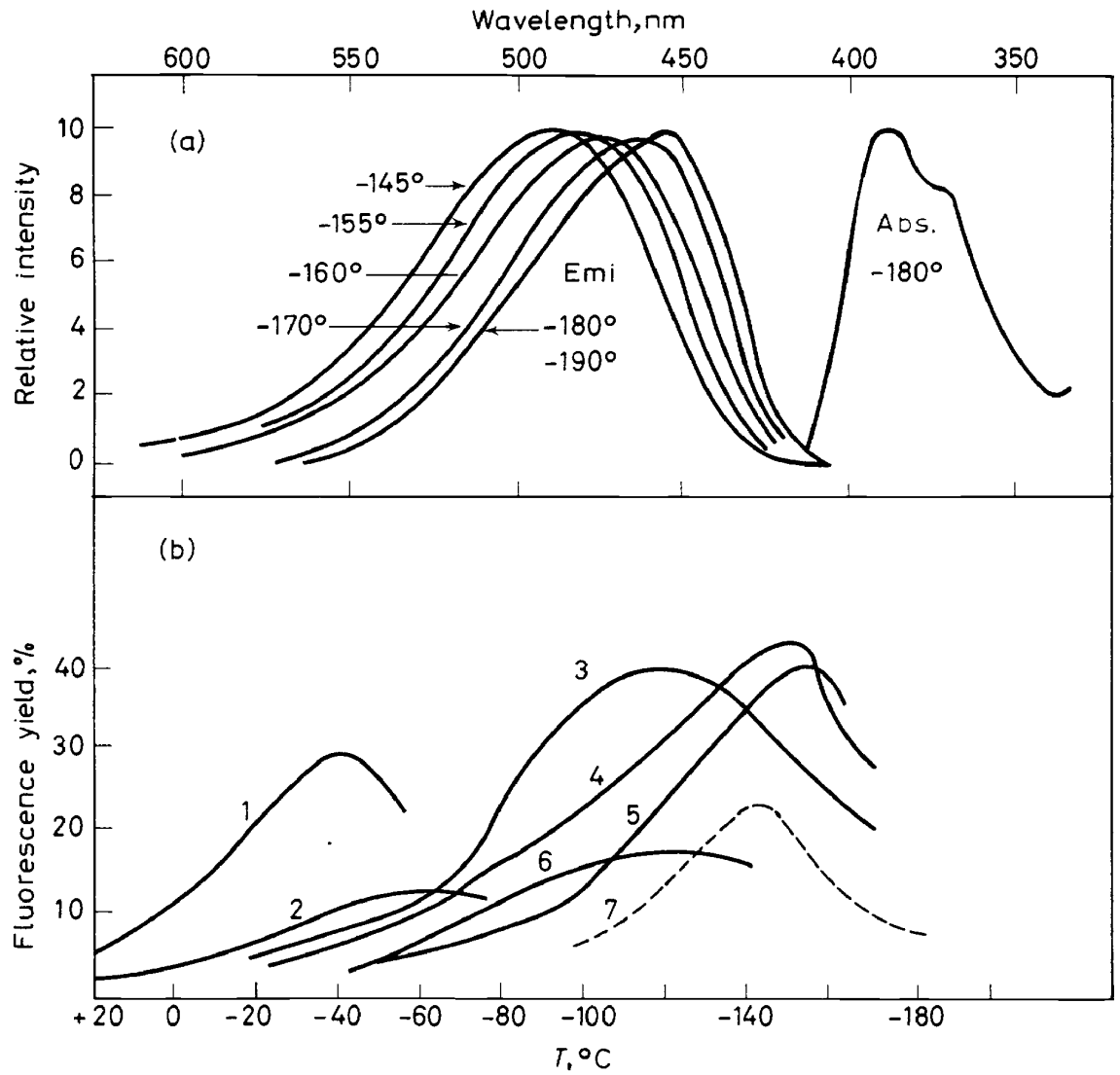

Figure 12. Fluorescence of TMD solutions. (a) : Fluorescence spectra in a $\mathrm{MCH}-\mathrm{MCP}$ solution at various temperatures, normalized to equal peak intensities. (b) : Quantum yields as a function of the temperature in various solvents: $1-\mathrm{PG}, 2-\mathrm{TA}, 3-1-\mathrm{P}-2-\mathrm{P}, 4-\mathrm{E}-\mathrm{M}, 5-\mathrm{MTHF}$, 6-Decalin, 7-MCH-MCP.

The blue shift of the fluorescence band is clearly a viscosity effect, and not confined to polar solvents. The obvious explanation is a relaxation of the Franck-Condon excited singlet state, reached on light absorption, and the surrounding solvent molecules. However, the existence of the effect in hydrocarbon solvents makes it impossible to blame only a re-orientation of of the dipolar solvent molecules around the excited solute molecule ${ }^{29}$, as suggested by Kortüm ${ }^{21}$, and one has to assume that the relaxation is actually 


\section{T. BERCOVICI, R. KORENSTEIN, K. A. MUSZKAT and E. FISCHER}

a change in the shape of the ${ }_{1}^{1} \stackrel{*}{S}$ molecule, slowed down by increasing solvent viscosity. A related effect was described by Stegemeyer ${ }^{30}$. The observed negligible temperature dependence of the triplet formation yield indicates that both the original and the relaxed ${ }^{1} S^{*}$ state undergo intersystem crossing with comparable rates. A relatively minor difference in these rates, or

Table 2. Fluorescence of TMD in various solvents and at various temperatures. The temperatures of maximal fluorescence yields and the respective viscosities are given below the solvent name [cf. Figure $12(b)$ and text]. Excitation at $340 \mathrm{~nm}$. D = Decalin, E-M = ethanol-methanol, $\mathrm{PG}=$ propylene glycol.

\begin{tabular}{|c|c|c|c|c|}
\hline Solvent & Onset & Midpoint & Endpoint & \\
\hline 2-MP & $\begin{array}{c}545 \\
-160^{\circ} \\
3\end{array}$ & $\begin{array}{r}530 \\
-170^{\circ} \\
4.8\end{array}$ & $\begin{array}{c}515 \\
-190^{\circ} \\
11\end{array}$ & $\begin{array}{l}\text { Wavelength, } \mathrm{nm} \\
\text { Temperature, }{ }^{\circ} \mathrm{C} \\
\log (\text { viscosity, } \mathrm{cP} \text { ) }\end{array}$ \\
\hline $\begin{array}{l}\text { MCH-MCP } \\
\left(-150^{\circ}\right) \\
(3)\end{array}$ & $\begin{array}{r}543 \\
-140^{\circ} \\
2.4\end{array}$ & $\begin{array}{r}522 \\
-160^{\circ} \\
3.8\end{array}$ & $\begin{array}{r}504 \\
-180^{\circ} \\
\sim 10\end{array}$ & $\begin{array}{l}{ }^{\mathrm{nm}} \\
{ }^{\circ} \mathrm{C} \\
\log (\mathrm{cP})\end{array}$ \\
\hline $\begin{array}{l}\mathrm{D} \\
\left(-125^{\circ}\right) \\
(8.5)\end{array}$ & $\begin{array}{c}537 \\
-80^{\circ} \\
2.6\end{array}$ & $\begin{array}{r}528 \\
-120^{\circ} \\
5.7\end{array}$ & $\begin{aligned} & 517 \\
&- 160^{\circ} \\
& \sim 16\end{aligned}$ & $\begin{array}{l}{ }^{\mathrm{nm}} \\
{ }^{\circ} \mathrm{C} \\
\log (\mathrm{cP})\end{array}$ \\
\hline $\begin{array}{l}\text { MTHF } \\
\left(-150^{\circ}\right) \\
(3.5)\end{array}$ & $\begin{array}{r}565 \\
-140^{\circ} \\
3\end{array}$ & $\begin{array}{r}535 \\
-162^{\circ} \\
5.8\end{array}$ & $\begin{array}{c}507 \\
-180^{\circ} \\
14\end{array}$ & $\begin{array}{l}\mathrm{nm} \\
{ }^{\circ} \mathrm{C} \\
\log (\mathrm{cP})\end{array}$ \\
\hline $\begin{array}{l}\text { E-M } \\
\left(-150^{\circ}\right) \\
(5)\end{array}$ & $\begin{array}{r}586 \\
-100^{\circ} \\
2\end{array}$ & $\begin{array}{r}550 \\
-143^{\circ} \\
3.5\end{array}$ & $\begin{array}{c}512 \\
-170^{\circ} \\
10\end{array}$ & $\begin{array}{l}{ }^{\mathrm{nm}} \mathrm{C} \\
\log (\mathrm{cP})\end{array}$ \\
\hline $\begin{array}{l}1-P-2-P \\
\left(-120^{\circ}\right) \\
(4.6)\end{array}$ & $\begin{array}{c}575 \\
-60^{\circ} \\
1\end{array}$ & $\begin{array}{r}545 \\
-120^{\circ} \\
4.6\end{array}$ & $\begin{array}{r}510 \\
-160^{\circ} \\
11\end{array}$ & $\begin{array}{l}{ }^{\mathrm{nm}} \\
{ }^{\circ} \mathrm{C} \\
\log (\mathrm{cP})\end{array}$ \\
\hline $\begin{array}{l}\text { TA } \\
\left(-60^{\circ}\right) \\
(8.7)\end{array}$ & $\begin{array}{r}530 \\
+25^{\circ} \\
1.2\end{array}$ & $\begin{array}{r}520 \\
-20^{\circ} \\
4\end{array}$ & $\begin{array}{c}510 \\
-76^{\circ} \\
13\end{array}$ & $\begin{array}{l}{ }^{\mathrm{nm}} \\
{ }^{\circ} \mathrm{C} \\
\log (\mathrm{cP})\end{array}$ \\
\hline $\begin{array}{l}\text { PG } \\
\left(-40^{\circ}\right) \\
(4.4)\end{array}$ & $\begin{array}{c}572 \\
0^{\circ} \\
2\end{array}$ & $\begin{array}{r}547 \\
-30^{\circ} \\
3.8\end{array}$ & $\begin{array}{c}522 \\
-78^{\circ} \\
8\end{array}$ & $\begin{array}{l}\mathrm{nm} \\
{ }^{\circ} \mathrm{C} \\
\log (\mathrm{cP})\end{array}$ \\
\hline
\end{tabular}

rather in the ratios $k_{\mathrm{F}} /\left(k_{\mathrm{F}}+k_{1}\right)$ and $k_{\mathrm{F}}^{\prime} /\left(k_{\mathrm{F}}^{\prime}+k_{1}^{\prime}\right)$ suffices to explain the decrease in $\Phi_{F}$ in the temperature region of the blue shift. The scheme emerging from the above description and the 'flash' paragraph is given in Figure 13. The discrete 'strained' and 'relaxed' levels in the scheme are an oversimplification, and it is probably more correct to assume a continuum of states between these two extremes ${ }^{30}$.

\section{Thermal reversion $B \rightarrow A$ and $\mathbf{C} \rightarrow \mathbf{A}$}

These spontaneous reactions have been studied before by $\mathrm{us}^{16,31}$, by Kortüm ${ }^{14}$ and, with flash methods, by Günthard ${ }^{25}$ and by Richtol ${ }^{32}$ and their associates. All investigators report a first-order behaviour, with activation energies depending somewhat on the substituents and the solvent, and 
ranging from $13-15 \mathrm{kcal} /$ mole for $\mathrm{B} \rightarrow \mathrm{A}$, with no significant difference between dianthrones substituted or not substituted in the 1 and $1^{\prime}$ positions.

During the present investigation we measured the kinetics of $\mathrm{B} \rightarrow \mathrm{A}$ and $\mathrm{C} \rightarrow \mathrm{A}$ for TMD and DMD in various solvents, and obtained the following activation energies, expressed in $\mathrm{kcal} / \mathrm{mole} \pm 0.5$ :

$\mathrm{B} \rightarrow \mathrm{A}, \mathrm{TMD}$ in $\mathrm{TA}-16$, in $\mathrm{CH}_{2} \mathrm{Cl}_{2}-14$, in $\mathrm{CS}_{2}-\mathrm{CHCl}_{3}(2: 1)-12.5$ $\mathrm{C} \rightarrow \mathrm{A}, \mathrm{TMD}$ in $\mathrm{CHCl}_{3}-10$, in $\mathrm{CH}_{2} \mathrm{Cl}_{2}-14$.

Measurements with TMD in $\mathrm{CH}_{2} \mathrm{Cl}_{2}$ at concentrations of $5 \times 10^{-5}$ and $5 \times 10^{-3} \mathrm{M}$ gave identical results. Deaeration also had no effect The results obtained by flash spectrophotometry were presented in a previous paragraph.

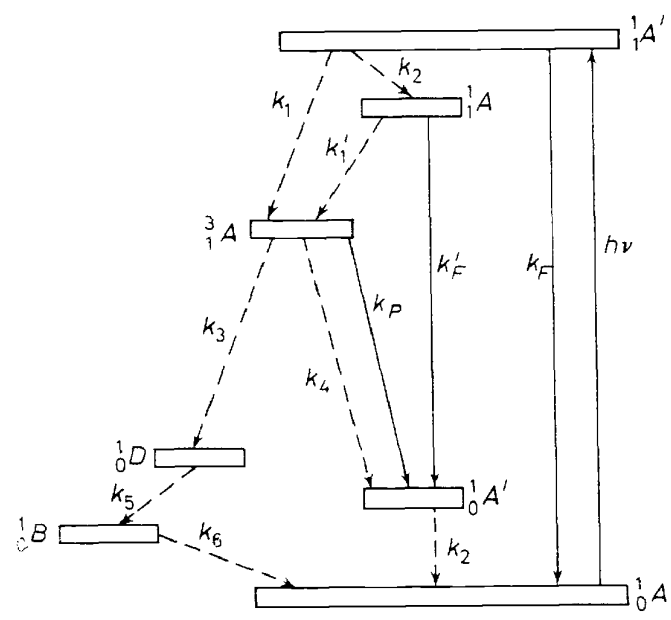

Strained levels are denoted with a prime

Figure 13. Term scheme. Full lines indicate radiative transitions and broken lines radiationless ones. Unrelaxed states are denoted by a prime. ${ }_{0}^{1} A,{ }_{0}^{1} B,{ }_{0}^{1} D$ denote the electronic ground states of the $\mathrm{A}, \mathrm{B}$ and $\mathrm{D}$ isomers, while ${ }_{1}^{1} A$ and ${ }_{1}^{3} A$ denote the first excited singlet and triplet states, respectively.

\section{The e.s.r. measurements and their correlation with changes in the optical absorption spectrum}

Many investigators have observed paramagnetism in DA and its derivatives not substituted in the 1 and $1^{\prime}$ positions. Recent papers by Becker ${ }^{33}$, Kortüm $^{24}$, Luckhurst $^{34}$, and their co-workers review the current situation, which may be summarized by stating that no correlation seems to exist between light-induced signals and reversible photocoloration. Our own experiments confirmed this conclusion, and showed that it applies also to the 1,1-di- 


\section{T. BERCOVICI, R. KORENSTEIN, K. A. MUSZKAT and E. FISCHER}

substituted dianthrones. However, in addition we observed a partial phototransformation of the $\mathbf{B}$ isomer of TMD, by u.v. light only, into a radical $\mathbf{R}$ characterized by both its e.s.r. spectrum centred at 3260 gauss, and its optical spectrum. The formation of this radical is thermally reversible. Figure 5(b) shows its optical absorption spectrum, calculated by extrapolation of the reversible change. Both the rate of photoformation of $\mathrm{R}$ and that of its thermal reversion to $B$ are sharply slowed down on cooling, and $R$ can therefore be observed only in the temperature range between about $-140^{\circ}$ and $-175^{\circ}$. The kinetics of the formation and disappearance of $R$ were followed both spectrophotometrically and in the e.s.r. spectrometer, and found to be identical within the rather large experimental error. The above reversible reaction is accompanied by the low-yield irreversible reactions already described in a previous paragraph, and may actually be a transient in these decompositions. $R$ is formed only from $B$, and only with light below about $400 \mathrm{~nm}$, with quantum yields much below those found for the formation of $B$. Some $R$ is formed even in solutions in MCH-2-MP, but the phenomenon is most pronounced in MTHF solutions.

No detailed e.s.r. study of $\mathbf{R}$ was made, but the conditions of its formation and disappearance make it likely that $\mathbf{R}$ is not identical with the free radicals whose e.s.r. signals have been described ${ }^{33,34}$.

\section{Infra-red measurements}

Methylene chloride was found to be the most suitable solvent for lowtemperature i.r. measurements, since it combines a low freezing point $\left(-97^{\circ}\right)$ with a high dissolving power and good i.r. properties. Additional measurements were carried out in chloroform and in carbon disulphide. $0.1 \mathrm{~mm}$ sodium chloride cells were used for measurements at wavenumbers below $2000 \mathrm{~cm}^{-1}$. Parallel experiments with the same solutions in $0.1 \mathrm{~mm}$ quartz cells were performed in the Cary 14, to establish the correlation between the changes in the u.v. and visible regions described before (formation of B and C) and those observed in the i.r. Under the experimental conditions employed, only isomer $\mathrm{C}$ was formed by $405 \mathrm{~nm}$ irradiation of TMD and DMD in $\mathrm{CH}_{2} \mathrm{Cl}_{2}$, while only $\mathrm{B}$ was formed with $1,1^{\prime}$-dimethoxy-DA and $1,2,1^{\prime}, 2^{\prime}-$ dibenzo-DA. The results for these four cases are shown in Figure 14 and in Table 3. The complexity of the compounds and the spectra makes it difficult to draw conclusions from the observed changes. Perhaps the only clear-cut fact is that the band at the assumed 'carbonyl' frequency ${ }^{35,36}$ at about 1670 $\mathrm{cm}^{-1}$ is attenuated in both $B$ and $C$ isomers, while a new strong band appears at around $1620 \mathrm{~cm}^{-1}$. Measurements at higher wavenumbers, in the hydroxyl range, were carried out in 1 and $10 \mathrm{~mm}$ Infrasil cells. Under these conditions no absorption bands appeared as a result of $405 \mathrm{~nm}$ irradiation. If both the 1660 and $1620 \mathrm{~cm}^{-1}$ bands are 'carbonyl' frequencies, this would be a very large shift, of the magnitude usually encountered in hydrogen-bonded carbonyl groups. ${ }^{18} \mathrm{O}$ labelling is planned, and should help in these assignments. Until then they will remain speculative, and the $1620 \mathrm{~cm}^{-1}$ band in particular may well be due to other groups. It appears premature to reconcile these results with the cyclic structure proposed in the introduction. Hopefully, other authors will comment on these findings. 
DIANTHRONE PHOTOCHROMISM 1950-1970

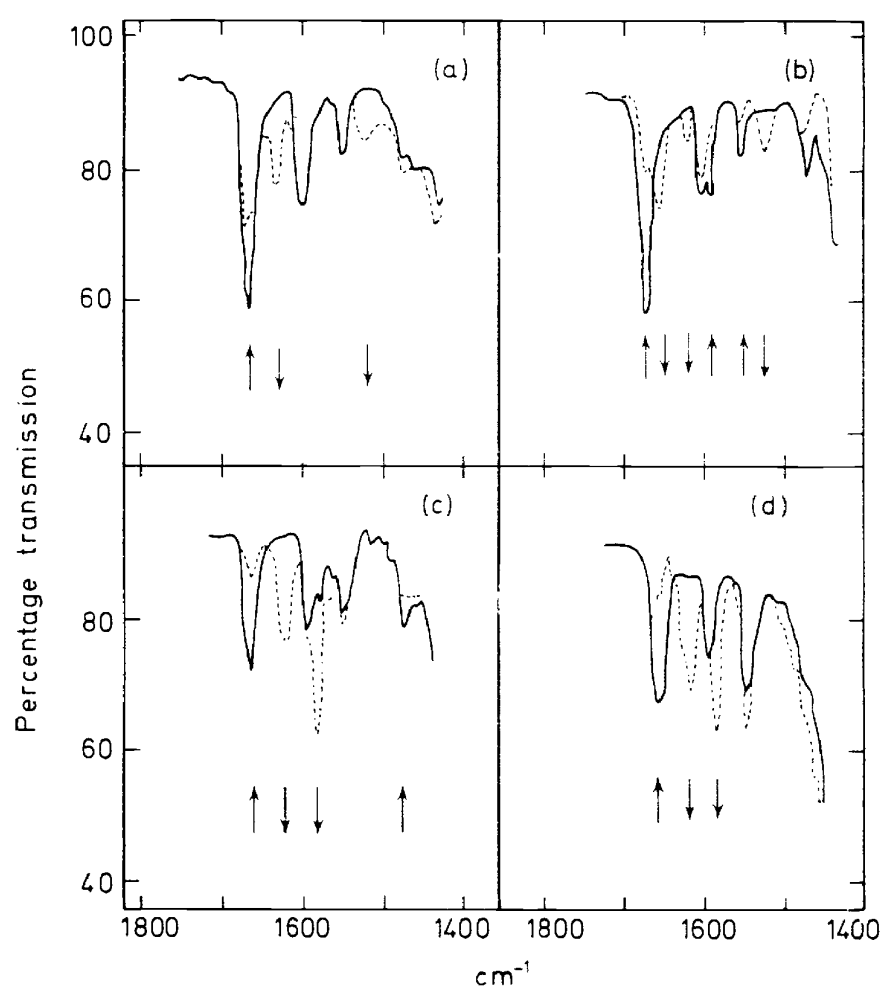

Figure 14. Infra-red absorption spectra at low temperatures. About $10^{-2} \mathrm{M}$ solutions in methylene chloride in $0.1 \mathrm{~mm}$ cells. Fult curves--before, broken curves-after irradiation at $405 \mathrm{~nm}$. (a) TMD at $-50^{\circ}$, (b) DMD at $-80^{\circ}$, (c) $1,1^{\prime}$-dimethoxy-DA at $-95^{\circ}$, (d) $1,2,1^{\prime}, 2^{\prime}$-dibenzo-DA at $-90^{\circ}$.

Table 3. Changes in i.r. absorption spectra of four compounds, resulting from $405 \mathrm{~nm}$ irradiation of their $c a .10^{-2} \mathrm{M}$ solutions in $\mathrm{CH}_{2} \mathrm{Cl}_{2}$ at the temperatures indicated. Strong new bands are underlined

\begin{tabular}{|c|c|c|c|c|c|c|c|c|}
\hline \multirow{2}{*}{$\begin{array}{l}\text { Compound, temp. }\left({ }^{\circ} \mathrm{C}\right) \\
\text { DMD, C isomer, }\left(-80^{\circ} \mathrm{C}\right)\end{array}$} & \multicolumn{4}{|c|}{ Disappearing bands, $\mathrm{cm}^{-1}$} & \multicolumn{4}{|c|}{ New bands, $\mathrm{cm}^{-1}$} \\
\hline & 1675 & 1585 & 1470 & 970 & 1650 & 1620 & 1525 & 1380 \\
\hline TMD, C isomer, $\left(-50^{\circ} \mathrm{C}\right)$ & 1670 & & & 1320 & (1660?) & $\underline{1630}$ & 1520 & 1310 \\
\hline $\begin{array}{l}\text { 1,1'-dimethoxy-DA, } \\
\text { B isomer, }\left(-95^{\circ}\right) \\
1,2,1^{\prime}, 2^{\prime} \text {-dibenzo-DA }\end{array}$ & 1665 & & 1475 & & & 1620 & $\underline{1580}$ & \\
\hline $\mathrm{B}$ isomer, $\left(-90^{\circ}\right)$ & 1660 & & & & (1670?) & 1620 & 1580 & \\
\hline
\end{tabular}



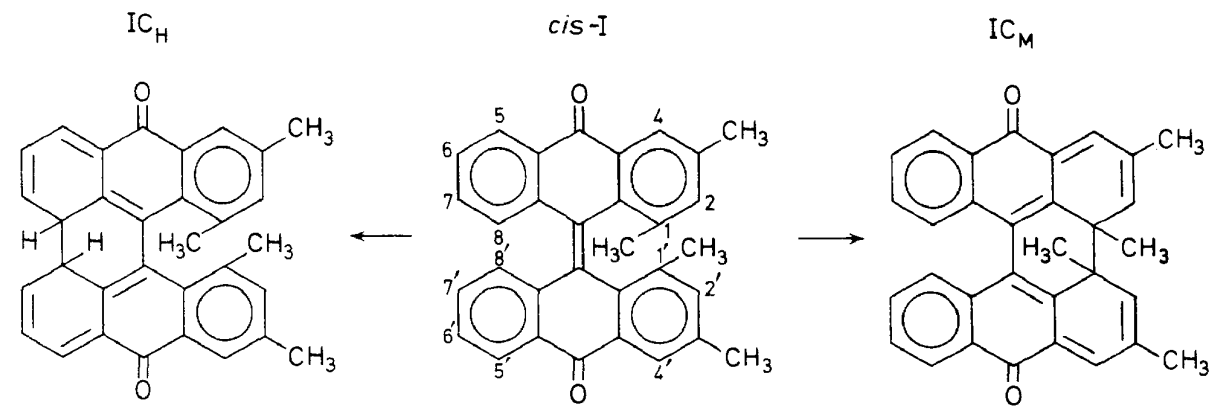

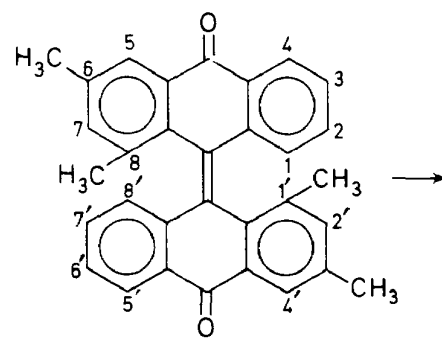

trans -I

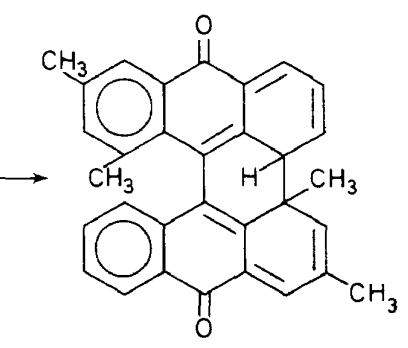

IC

\section{The n.m.r. measurements}

The n.m.r. spectra of DMD and TMD were first taken at room temperature. The suggested assignments in TMD are as follows: 1.44 p.p.m.--1- $\mathbf{C H}_{3}$ group (shielded by the aromatic ring in the opposite half of the molecule); 2.4--3- $\mathrm{CH}_{3}$ group; 6.89 and 6.91 -hydrogen 8 (shielded by the opposite ring and split by hydrogen 7) and hydrogen 2; 7.1 and 7.4 triplets-hydrogens 6 and 7, each split by the neighbouring two hydrogens; 7.8-hydrogen 4; 8 -hydrogen 5 , shifted downfield by the carbonyl group and split by hydrogen 6.

The $\mathrm{B}$ and $\mathrm{C}$ isomers were formed as described in the experimental part. For technical reasons, only the $\mathrm{C}$ isomer of DMD could be measured. Since only partial transformation into the coloured isomers can be achieved, the n.m.r. spectra after irradiation all contain the attenuated lines of the starting material, besides new lines. Irradiations were carried out under conditions closely similar to those employed in the spectrophotometric measurements. The identity of the $\mathrm{B}$ and $\mathrm{C}$ isomers was further corroborated by the kinetics of the thermal disappearance of the lines assigned to these isomers, as compared with the disappearance of the absorption at $480 \mathrm{~nm}$ and $660 \mathrm{~nm}$.

The spectra resulting from partial conversion into $\mathrm{C}$ are shown in Figures 15 and 16. The new lines ascribed to the $C$ isomer were as follows: For TMD-8.16, 6.4, 2.05 and 1.67 p.p.m. For DMD-8.18, 6.73, 6.5 and 1.74 p.p.m. (The doublet at 2.3 p.p.m. is due to an irreversible process.) A comparison of the two compounds shows that the 1-methyl peak is shifted downfield by 0.26 p.p.m. in TMD and 0.32 in DMD. The 3-methyl peak is 
shifted upfield by 0.35 p.p.m. The assignment of the other hydrogens is still doubtful.

In trying to reconcile the above results with the suggested cyclic structure for the $\mathbf{C}$ isomer, we have to remember that the two isomers cis-I and trans-I can in principle cyclize into three different isomeric products : $\mathrm{IC}_{\mathrm{M}}, \mathrm{IC}_{\mathrm{H}}, \mathrm{IC}$. The n.m.r. results for $\mathrm{C}$ fit both $\mathrm{IC}_{\mathrm{M}}$ and IC, but cannot distinguish between them. The 1-methyl peak is shifted downfield because it is removed from the shielding opposite aromatic system, while the 3-methyl peak is shifted upfield because the methyl group is transformed from an aromatic into a vinylic one. The 6.4 p.p.m. peak may then be assigned to hydrogens 2 and 4 .

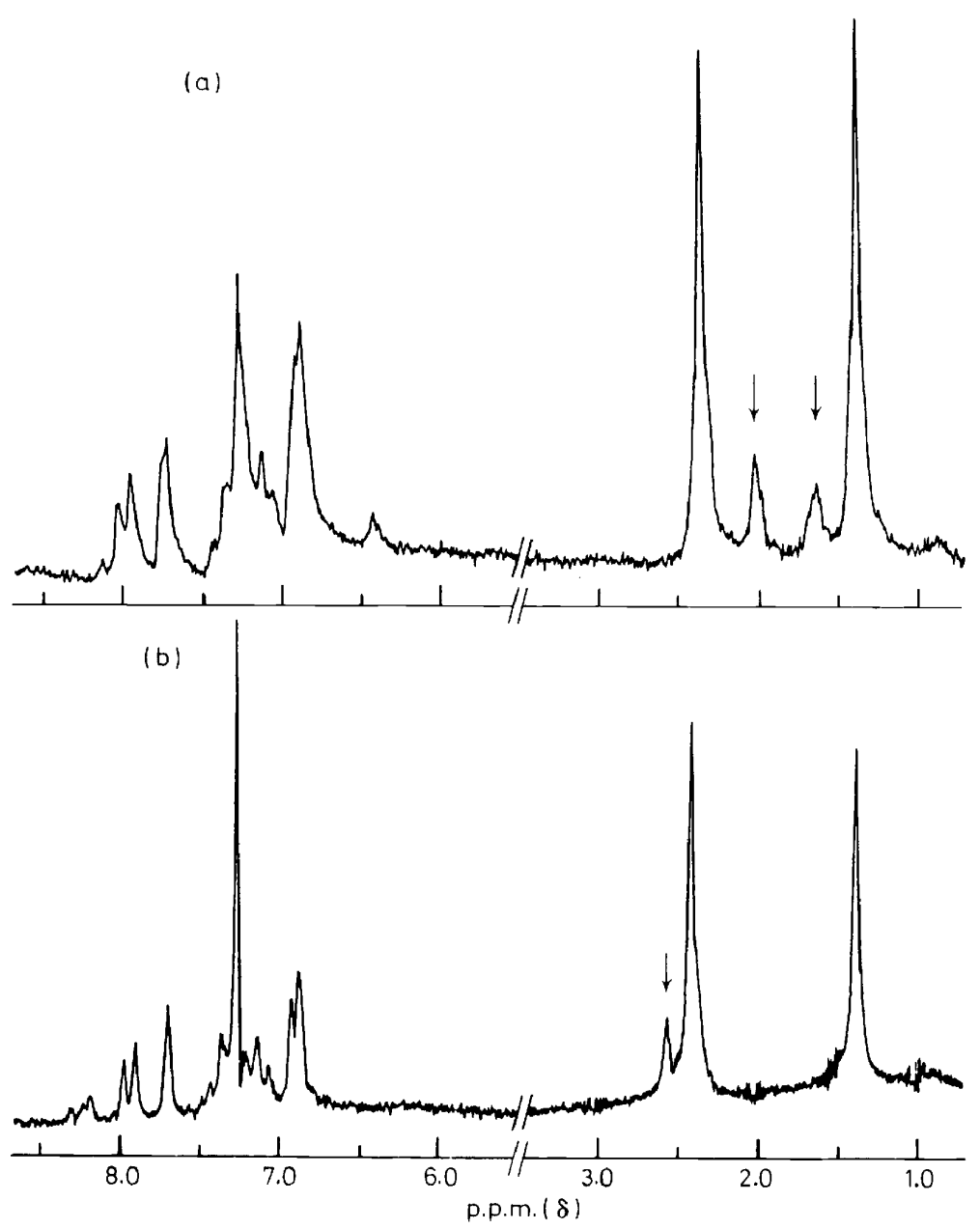

Figure 15. The n.m.r. spectra at low temperatures. (a) TMD in $\mathrm{CDCl}_{3}$ at $-55^{\circ}$, after partial conversion into $\mathrm{C}$ isomer. (b) TMD in $\mathrm{CS}_{2}-\mathrm{CDCl}_{3}(2: 1)$, after partial conversion into $\mathrm{B}$ isomer at $-85^{\circ}$. 
The decision between $\mathrm{IC}_{\mathrm{M}}$ and $\mathrm{IC}$ was eventually made on the basis of the extent of conversion. Spectrophotometric observations had shown that the maximal extent of photoconversion under the prevailing experimental conditions was about 50 per cent in TMD and 70 per cent in DMD, immediately after irradiation. The manipulations necessary in connection with the
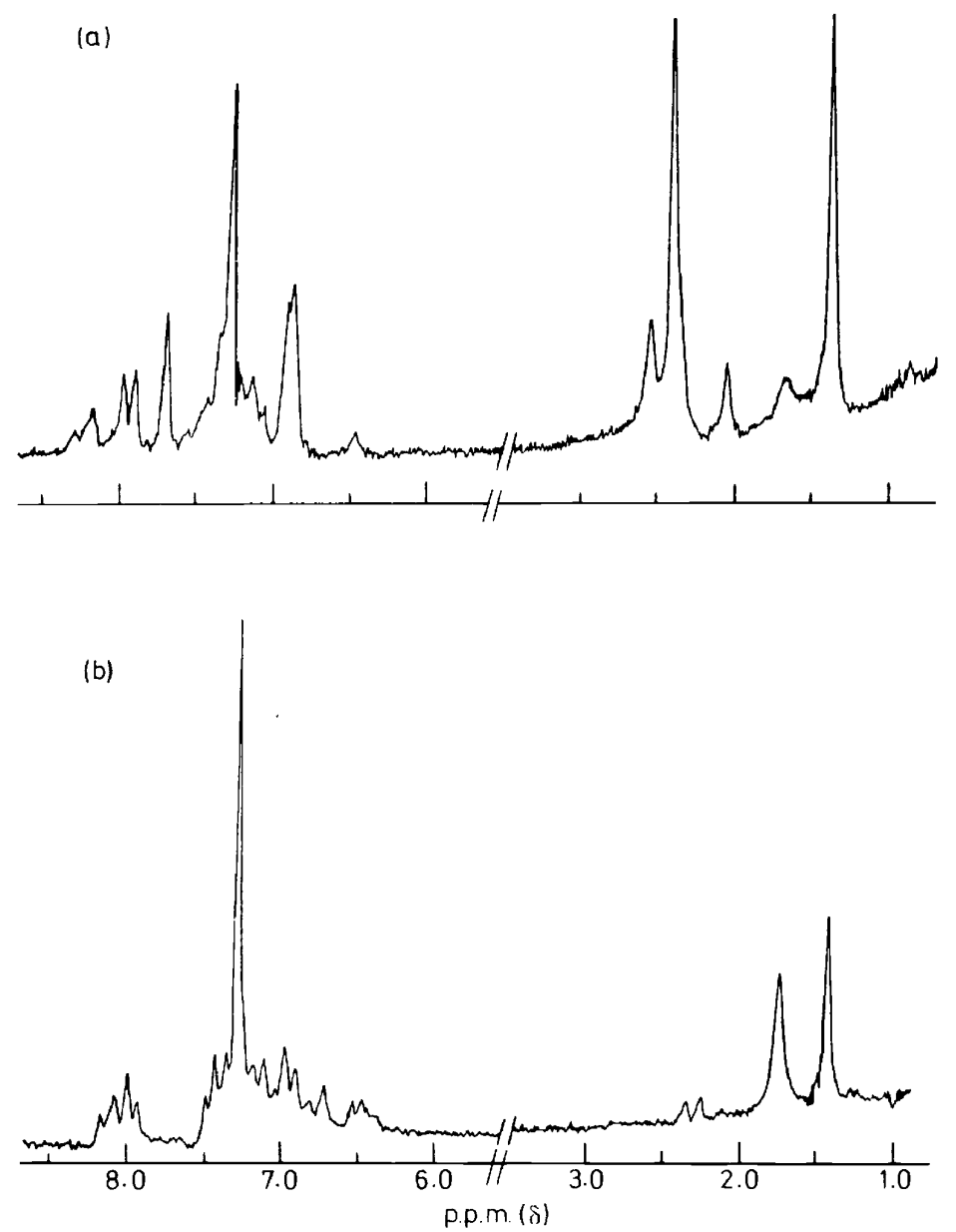

Figure 16. The n.m.r. spectra at low temperatures. (a) TMD in $\mathrm{CS}_{2}-\mathrm{CDCl}_{3}(2: 1)$ at $-85^{\circ}$, after partial conversion into $\mathrm{B}+\mathrm{C}$ isomers. (b) $\mathrm{DMB}$ in $\mathrm{CDCl}_{3}$, after partial conversion into $\mathrm{C}$ isomer at $-55^{\circ}$.

n.m.r. measurements can only reduce this percentage, because of the thermal decay. However, the n.m.r. spectrum of DMD after irradiation (Figure 16) indicates that 50 per cent of the methyl groups in the mixture are of the new type. If IC were the irradiation product, only complete conversion would 
lead to this result. Since this is clearly impossible, we have to conclude that, if a cyclic structure is formed, it has to be $\mathrm{IC}_{\mathrm{M}}$.

The $\mathrm{B}$ isomer was studied in TMD. In the solvent used $\left(\mathrm{CS}_{2}-\mathrm{CDCl}_{3}\right)$, $405 \mathrm{~nm}$ irradiation at $-90^{\circ}$ results in the formation of $B$ and $C$, with the latter predominating. In order to achieve appreciable conversion into $\mathrm{B}$, alternative irradiations at 405 and $546 \mathrm{~nm}$ had to be used. Even so, the extent of conversion was rathen low. The only clear new peak was at 2.55 p.p.m. This was also proved by kinetic experiments after irradiation at $405 \mathrm{~nm}$, when both $\mathrm{B}$ and $\mathrm{C}$ are formed. When such a solution was warmed to $-50^{\circ}$, where $\mathrm{B}$ is known to decay much faster than $\mathrm{C}$, the 2.55 peak disappeared, while the peaks at 1.7 and 2.05 p.p.m. remained.

The new peak at 2.55 , Figure 15 , is formed at the expense of that at 1.36 (assigned to the 1-methyl group), while the 2.4 peak (assigned to the 3 -methyl group) remains unchanged. The conclusion is that the 1-methyl peak has been shifted from 1.36 to 2.55 p.p.m., and any suggested structure for B has therefore to explain why only the n.m.r. peak of the 1-methyl group is affected by the transformation $\mathrm{A} \rightarrow \mathrm{B}$.

If we assume that $B$ too is a cyclic compound, similar to $C$, then structure $\mathrm{IC}_{\mathrm{H}}$ might fit the results, with both the 1 and 3 methyl groups now being in the usual range of aromatic methyls. Basically, such a structure would explain why $C$ is observed only in the derivatives methylated in the 1 and 1 ' positions, while B is found in DA and all its derivatives. However, it would not explain the much greater photostability of $1,1^{\prime}$-disubstituted compounds though, as we proved, even in DA the B isomer is not directly involved in the photochemical decomposition (cf. next paragraph).

Other possible structures which might be reconciled with the n.m.r. results, but probably not with the optical absorption spectra, are (1) a simple isomerization around the central double bond, assuming that the starting cis compound is converted into trans, and (2) a twisted configuration in which the 1,1'-methyl groups are removed from the shielding effect of the opposite rings. In this context we measured the n.m.r. spectrum of dianthronyl, XI, in which the central bond is a single one, around which restricted rotation can take place. Here the methyl peaks appeared at 2.38 and 2.7 p.p.m., i.e. close to each other, as also observed in B above.

\section{Thermochromism and irreversible photoreactions of dianthrone proper}

Solutions of DA in diphenylether have a single absorption band in the visible region whose intensity increases with temperature ('thermochromism'). At $235^{\circ}$ the peak is at $655 \mathrm{~nm}$ and shifts to $665 \mathrm{~nm}$ at $100^{\circ}$. This may be compared with the single peak observed for the B isomer in the photochromism of DA in MTHF [Figure 3(a)]. This photochromic peak is blue-shifted from $695 \mathrm{~nm}$ at $-175^{\circ}$ to $675 \mathrm{~nm}$ at $-60^{\circ}$. There is thus good reason to believe that here, as in the case of the various derivatives of DA investigated ${ }^{3,21,37}$, the 'photochromic' coloured isomer B and the 'thermochromic' coloured isomer formed at high temperatures in a thermal equilibrium are identical. The absorption spectrum of such solutions of DA in diphenylether was not affected by oxygen even at $235^{\circ}$. The same holds for the B isomer formed by u.v. irradiation of, e.g., a solution in 1-P-2-P at $-160^{\circ}$. When such a solution, containing either virtually pure $\mathrm{B}$ isomer, or a mixture of starting material and 
$\mathrm{B}$, was heated to $-80^{\circ}$ or higher, and oxygen bubbled through, no spectral change was observed. B thus does not undergo any thermal reaction, except the spontaneous reversion to the colourless $\mathrm{A}$ isomer above about $-50^{\circ}$.

The well-known irreversible photoreactions ${ }^{11,32,33}$ of DA and some of its derivatives cannot therefore be due to secondary intermolecular reactions of the $B$ isomer, produced by irradiation of DA.

Moreover, if DA is first converted completely into the B isomer by $405 \mathrm{~nm}$ irradiation at very low temperatures [Figure 3(a)], and the irradiation then continued at $-150^{\circ}$, no further changes are observed. If, however, DA itself is irradiated directly at $-150^{\circ}$, efficient irreversible reactions take place [Figure 3(d)]. This shows conclusively that the B isomer is light-stable, and therefore not a direct precursor in the sequence of the irreversible photoreactions. If a mixture of DA and its $\mathrm{B}$ isomer (formed at $-175^{\circ}$ by partial conversion into B with $405 \mathrm{~nm}$ light), is then irradiated at $-60^{\circ}$ with light at $546+578 \mathrm{~nm}$, no reaction takes place. This shows that excited B molecules do not react under these conditions, but of course still allows for the possibility of a reaction between $B$ and photo-excited DA. When the same 1:1 mixture of DA and B was irradiated at $-150^{\circ}$ with $405 \mathrm{~nm}$ light, a fast photocomposition of DA, similar to the one described for pure DA, was observed, while B was not affected. However, this was followed by a slower thermal reaction [curves $2 \rightarrow 3$ in Figure 3(d)] during which the concentration of $B$ decreased. Further irradiation at $405 \mathrm{~nm}$ resulted in a mixture of $B$ (about one third of its original quantity) and the decomposition products. All this indicates that in the efficient irreversible photoreactions of DA, which do take place at all but the lowest temperatures, the primary active units are excited DA molecules, probably undergoing some reaction which competes with the formation of B and does not involve B at all. The latter enters only secondary reactions with some long-lived (radical?) irradiation product of DA. (The approximate viscosity, in cP, of MTHF is $10^{3.5}$ at $-150^{\circ}, 10^{5.3}$ at $-160^{\circ}$, and $10^{11}$ at $-175^{\circ}$ ) Generally similar photoreactions were observed with solutions of DA in 1-P-2-P.

Perhaps the most interesting irreversible reaction of DA is the formal tautomerization to dihydrohelianthrone (= dihydroxydibenzopyrene), VI, first described by Brockman ${ }^{11}$. Formally VI results from the movement of the two aliphatic hydrogen atoms in IV to the two oxygens. This compound was isolated by Brockman ${ }^{11}$. In the absence of oxygen and oxidants it is stable at room temperature. It is characterized by peaks at 610 and $575 \mathrm{~nm}$ (in 1-P-2-P). We observed its formation only in deaerated polar solvents, in particular in alcohols. In 1-P-2-P solutions, VI results from u.v. irradiation at temperatures between $-100^{\circ}$ and room temperature, in a rather efficient photoreaction. It appears that substantial conversion into VI can be achieved. If only part of the DA is converted into VI, the latter then undergoes a slow thermal reaction with DA, to give helianthrone, VII, and dianthronol, IX. VII has peaks at about $450,370,380$, and $317 \mathrm{~nm}$, while IX is characterized by sharp peaks at about $425,405,385$ and $370 \mathrm{~nm}$. Similar though less pronounced reactions were observed at lower temperatures, in MTHF solutions, as described in sections B and D of Figure 3. At $-160^{\circ}$, irradiation results in a mixture of the B isomer, with some VI (its peaks are submerged in that of B), and some VII and IX. After heating and recooling to $-160^{\circ}$ [Figure $\left.3(\mathrm{c})\right]$, 
all that remains is a mixture of VII and IX. The same irradiation at $-150^{\circ}$ [Figure 3(d), curve 2] forms just a trace of the B isomer $(700 \mathrm{~nm})$, some VI $(580+625 \mathrm{~nm})$, and some VII and IX (sharp peaks at shorter wavelengths). After 30 minutes at this temperature (curve 3), more VII and IX are formed. The same solution brought to room temperature has the spectrum given in the insert, Figure 3(d), curve 4. In the presence of oxygen, VI is rapidly oxidized to VII.

No VI was observed in non-polar solvents and one may conclude that, whatever the mechanism of the tautomerization DA $\rightarrow$ VI, the polar solvent molecules have some function in the hydrogen transfer. The involvement of B in the formation of VI again remains an open question. At any rate the process is obviously not an intramolecular one, and its attenuation at temperatures below $-100^{\circ}$ in $1-\mathrm{P}-2-\mathrm{P}$ is probably a result of restricted diffusion (cf. ref. 33b).

In non-polar solvents (iso-octane, $\mathrm{MCH}-\mathrm{T}, \mathrm{MCH}-\mathrm{MCP}$ ), other irreversible reactions, including formation of IV and IX, were observed, but were not followed in detail. As described in the first paragraph, in non-polar solvents, just as in polar ones, B is the major product of irradiation of DA at the lowest temperatures, in rigid media.

In aromatic solvents, such as benzene or toluene, the irreversible photoreactions are less pronounced, and B can be seen in DA at room temperature with the flash technique.

\section{CONCLUSIONS}

(1) The coloured isomer B and the thermochromic coloured isomer are identical in all dianthrones, including those undergoing easy photo-oxidation to helianthrone. (2) B is remarkably stable towards thermal and photooxidation. (3) Structures IV and V are most suggestive as precursors of the end products VII, VIII, X. (4) It is difficult to reconcile these three conclusions with the assumption that $B$ has structure IV. (5) The i.r. data seem to indicate that the carbonyl band of the parent compound disappears during the conversion into $B$, and is replaced by an unidentified new band. Whether or not it is also a carbonyl band, the carbonyl seems to be involved in the formation of B much more deeply than what one would expect for IV or for a twisted isomer of I. However, for the $\mathrm{C}$ isomer this may not be so. (6) The n.m.r. results for the $\mathbf{C}$ isomer could fit structure IV, but for B the results are at least ambiguous. (7) The photochromism of dixanthylene ${ }^{31}$, II, which has recently received renewed attention ${ }^{37,38}$, is at least superficially similar to that of DA, although it takes place with much lower quantum yields ${ }^{38}$. This would indicate that the carbonyl group is not directly involved in the formation of $\mathbf{B}$.

In this context one should mention Grabowski's polarographic study of thermochromic DA, in which he showed that the B isomer undergoes reversible oxidation-reduction (to bianthranol, IX), while A is reduced irreversibly. Grabowski ${ }^{15}$ concludes that B cannot have a cyclic structure, such as IV, and suggests the 'twisted' structure proposed earlier. Again it appears difficult to assign the observed absorption spectrum of $B$ to such a twisted isomer, or to explain the i.r. spectra, and the much greater photostability of $\mathrm{B}$, as compared to $\mathrm{A}$. 


\section{T. BERCOVICI, R. KORENSTEIN, K. A. MUSZKAT and E. FISCHER}

To sum up, the cyclic structure IV may not be the correct one for the B isomer, and new ideast and suggestions are welcome, as long as they do not clash with the above results.

Under these circumstances one may well ask what was the point in all these experiments, and how they relate to photochemistry in general. To my mind the interest in these results lies not only in the attempted elucidation of the structure of these colourful isomers. It appears to me that the photochemistry of these compounds provides a beautiful example of environmental control of the extent and the directions of photoreactions, both intra- and intermolecular, reversible and irreversible, in one single system.

\section{ACKNOWLEDGEMENTS}

The authors are grateful to $\mathrm{Mr} \mathrm{M}$. Kaganowitch for the synthesis of the compounds, to Mrs G. Fischer for the investigation of the emission and i.r. spectra, and the quantum yields, and to Mrs N. Castel and Miss M. Kazes for technical assistance.

\section{REFERENCES}

${ }^{1}$ R. Kornstein, K. A. Muszkat and E. Fischer, Israel J. Chem. 8. 273 (1970).

${ }^{2}$ T. Bercovici, G. Fischer and E. Fischer, Israel J. Chem. 8, 277 (1970).

${ }^{3}$ E. Fischer, Fortschr. Chem. Forsch. 7, 605 (1967).

${ }^{4}$ R. Dessauer and J. P. Paris, Advanc. Photochem. 1, 275 (1963).

${ }^{5}$ S. Dähne, Z. Wiss. Photogr., Photophysik, Photochem. 62, 183 (1968).

This review brings a very comprehensive list of references.

${ }^{6}$ R. N. Macnair, Photochem. Photobiol. 6, 779 (1967).

${ }^{7}$ K. Maeda and T. Hayashi, Bull. Chem. Soc. Japan, 43, 429 (1970).

${ }^{8}$ K. A. Muszkat and E. Fischer, J. Chem. Soc. B, 662 (1967).

${ }^{9}$ H. Blattmann, D. Mende, E. Heilbronner, R. J. Molyneux and V. Boekelheide, J. Am. Chem. Soc. 87, 130 (1965).

† During this symposium Dr Chapman suggested the structure given below, in analogy with a similar proposed intermediate in anthrone photoreactions:

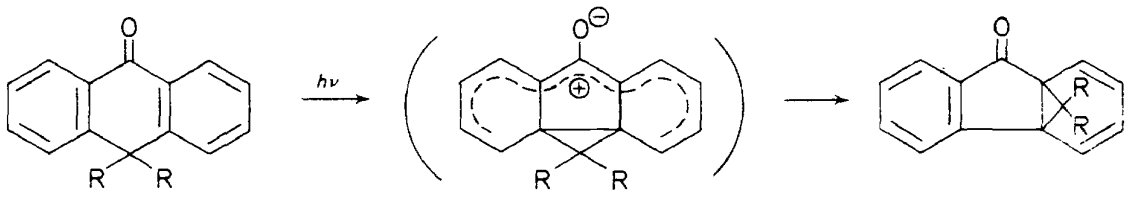<smiles>O=C1c2ccccc2C(=C2c3ccccc3C(=O)c3ccccc32)c2ccccc21</smiles>

This suggestion might well explain the i.r. results, and will be taken up. The authors are grateful to Dr Chapman for making this proposal available to them. 


\section{DIANTHRONE PHOTOCHROMISM 1950-1970}

${ }^{10}$ R. Becker and J. Kolc, J. Phys. Chem. 72.997 (1968); 71, 4045 (1967).

${ }^{11}$ H. Brockman and R. Muhlmann. Chem. Ber. 81, 467 (1948); 82, 348 (1949).

${ }_{12}$ A. Schönberg and K. Junghans, Chem. Ber. 98, 2539 (1965).

${ }^{13}$ R. Lorenz, U. Wild and J. R. Huber, Photochem. Photobiol. 10, 233 (1969).

14 G. Kortüm and G. Bayer, Ber. Bunsenges. Phys. Chem. 67, 24 (1963).

${ }^{15}$ Z. R. Grabowski and M. S. Balasiewicz, Trans. Faraday Soc. 64, 3346 (1968).

${ }^{16}$ T. Bercovici and E. Fischer, Israel J. Chem. 7, 127 (1969).

${ }^{17}$ T. Bercovici and E. Fischer, Molec. Photochem. 1, 23 (1969).

${ }^{18}$ C. Balny, P. Douzou, T. Bercovici and E. Fischer, Molec. Photochem. 1. 225 (1969).

${ }^{19}$ E. Fischer, Molec. Photochem. 2, 99 (1970).

${ }^{20}$ Y. Hirshberg, J. Am. Chem. Soc. 78, 2304 (1956).

${ }^{21}$ G. Kortüm and H. Bach, Z. Phys. Chem. N.F. 46, 305 (1965).

22 G. Zimmerman, L. Chow and U.-J. Paik, J. Am. Chem. Soc. 80, 3528 (1958).

${ }^{23}$ S. Malkin and E. Fischer, J. Phys. Chem. 66, 2482 (1962).

24 (a) G. Kortüm and W. Zoller, Chem. Ber. 100, 280 (1967);

(b) G. Kortüm and K.-W. Koch, Chem. Ber. 100, 1515 (1967).

25 J. R. Huber, U. Wild and H. H. Günthard, Helv. Chim. Acta, 50, 589 and 841 (1967).

${ }^{26}$ H. Greenspan and E. Fischer, J. Phys. Chem. 69, 2466 (1965), and recent unpublished results by $\mathrm{G}$. and E. Fischer.

27 (a) A. C. Ling and J. E. Willard. J. Phys. Chem. 72.1918 and 3349 (1968).

(b) G. V. Salis and H. Labhart, J. Phys. Chem. 72, 752 (1968).

${ }^{28}$ I. Berlman: Fluorescence Spectra of Aromatic Molecules, Academic Press: New York (1965).

${ }^{29}$ E. Lippert, Ber. Bunsenges. Phys. Chem. 61, 962 (1957).

${ }^{30}$ H. Stegemeyer. Ber. Bunsenges. Phys. Chem. 72, 335 (1968), and private communication.

${ }^{31}$ Y. Hirshberg and E. Fischer, J. Chem. Soc. 629 (1953).

${ }^{32}$ L. J. Dombrowski, C. L. Groncki, R. L. Strong and H. H. Richtol, J. Phys. Chem. 73, 3481 (1969).

${ }^{33 a}$ L. A. Harrah and R. Becker, J. Phys. Chem. 69, 2487 (1967).

${ }^{33 b}$ R. Becker and C. A. Earhart, J. Am. Chem. Soc. 92, 5049 (1970).

${ }^{34}$ I. Agranat, M. Rabinowitz, H. R. Fąlle, G. R. Luckhurst and J. N. Ockwell, J. Chem. Soc. B, 294 (1970).

${ }^{35}$ D. Hadži and N. Sheppard, J. Am. Chem. Soc. 73, 5460 (1951).

${ }^{36}$ M.-L. Josien and N. Fuson, Bull. Soc. Chim. Fr. 19. 389 (1952).

${ }^{37}$ G. Kortüm and P. Krieg, Chem. Ber. 102, 3033 (1969) and earlier papers cited there.

${ }^{38} \mathrm{E}$. Fischer, unpublished results.

${ }^{39}$ C. R. Goldschmidt, private communication. 